\title{
Analysis of Epithelial and Mesenchymal Markers in Ovarian Cancer Reveals Phenotypic Heterogeneity and Plasticity
}

\author{
Robert Strauss ${ }^{1,6}$, Zong-Yi Li ${ }^{1}$, Ying Liu ${ }^{1}$, Ines Beyer ${ }^{1}$, Jonas Persson ${ }^{1}$, Pavel Sova ${ }^{2}$, Thomas Möller ${ }^{3}$, Sari \\ Pesonen $^{4}$, Akseli Hemminki ${ }^{4}$, Petra Hamerlik ${ }^{6,7}$, Charles Drescher ${ }^{5}$, Nicole Urban ${ }^{5}$, Jiri Bartek ${ }^{6,7}$, André \\ Lieber ${ }^{1,2 *}$
}

1 Division of Medical Genetics, University of Washington, Seattle, Washington, United States of America, 2 Department of Pathology, University of Washington, Seattle, Washington, United States of America, 3 Department of Neurology, University of Washington, Seattle, Washington, United States of America, 4 Cancer Gene Therapy Group, University of Helsinki and Helsinki University Central Hospital, Helsinki, Finland, $\mathbf{5}$ Fred Hutchinson Cancer Research Center, Seattle, Washington, United States of America, 6 Danish Cancer Society, Department of Cell Cycle and Cancer, Center for Genotoxic Stress Research, Copenhagen, Denmark, 7 Laboratory of Genomic Integrity and Institute of Molecular and Translational Medicine, Palacky University, Olomouc, Czech Republic

\begin{abstract}
In our studies of ovarian cancer cells we have identified subpopulations of cells that are in a transitory E/M hybrid stage, i.e. cells that simultaneously express epithelial and mesenchymal markers. E/M cells are not homogenous but, in vitro and in vivo, contain subsets that can be distinguished based on a number of phenotypic features, including the subcellular localization of E-cadherin, and the expression levels of Tie2, CD133, and CD44. A cellular subset (E/M-MP) (membrane Ecadherin $^{\text {low }} /$ cytoplasmic E-cadherin ${ }^{\text {high }} / \mathrm{CD} 133^{\text {high }}, \mathrm{CD}_{4} 4^{\text {high }}, \mathrm{Tie}^{\text {low }}$ ) is highly enriched for tumor-forming cells and displays features which are generally associated with cancer stem cells. Our data suggest that E/M-MP cells are able to differentiate into different lineages under certain conditions, and have the capacity for self-renewal, i.e. to maintain a subset of undifferentiated E/M-MP cells during differentiation. Trans-differentiation of E/M-MP cells into mesenchymal or epithelial cells is associated with a loss of stem cell markers and tumorigenicity. In vivo xenograft tumor growth is driven by E/M-MP cells, which give rise to epithelial ovarian cancer cells. In contrast, in vitro, we found that E/M-MP cells differentiate into mesenchymal cells, in a process that involves pathways associated with an epithelial-to-mesenchymal transition. We also detected phenotypic plasticity that was dependent on external factors such as stress created by starvation or contact with either epithelial or mesenchymal cells in co-cultures. Our study provides a better understanding of the phenotypic complexity of ovarian cancer and has implications for ovarian cancer therapy.
\end{abstract}

Citation: Strauss R, Li Z-Y, Liu Y, Beyer I, Persson J, et al. (2011) Analysis of Epithelial and Mesenchymal Markers in Ovarian Cancer Reveals Phenotypic Heterogeneity and Plasticity. PLoS ONE 6(1): e16186. doi:10.1371/journal.pone.0016186

Editor: Donald Gullberg, University of Bergen, Norway

Received August 27, 2010; Accepted December 13, 2010; Published January 14, 2011

Copyright: (c) 2011 Strauss et al. This is an open-access article distributed under the terms of the Creative Commons Attribution License, which permits unrestricted use, distribution, and reproduction in any medium, provided the original author and source are credited.

Funding: The work was supported by NIH grants R01 CA080192, R01 HLA078836, and Pacific Ovarian Cancer Research Consortium/Specialized Program of Research Excellence in Ovarian Cancer Grant P50 CA83636. The funders had no role in study design, data collection and analysis, decision to publish, or preparation of the manuscript.

Competing Interests: The authors have declared that no competing interests exist.

*E-mail: lieber00@u.washington.edu

\section{Introduction}

It has been suggested that tumor re-growth, as well as chemotherapy resistance and metastasis, are dependent on a small sub-population of cancer cells within the tumor that are thought to represent cancer stem cells (CSCs). A defining hallmark of stem cells, in both normal and malignant tissue, is the ability to self-renew but simultaneously give rise to daughter cells that are committed to differentiation into phenotypes that often cross lineages. To achieve this, stem cells can undergo an asymmetric cell division whereby they segregate cell fate determinants into only one of the two daughter cells [1]. In adult mammals, stem cells have been characterized for a number of tissues, including the blood system, central nervous system, muscle, colon, breast, and bone/cartilage.

For cancer stem cells in solid tumors, much can be learned from studies of hematopoietic stem cells (HSC) for which it has been shown that the transplantation of a single cell into a myeloablated recipient can reconstitute the entire blood system. This definitive HSC gives rise to a hierarchy of pluripotent progenitors that become progressively restricted in their differentiation potential. Leukemia is thought to originate either from HSGs that acquired genetic or epigenetic changes and became partially differentiated and tumorigenic, or from progenitors that acquired the capacity to self-renew [2]. The existence of stem cells for certain types of leukemia is strongly supported by lentiviral tagging of human acute myelogenous leukemia cells and the observation of individual clones present in NOD-SCID mice after serial transplantation of the tagged cells [3]. Studies of leukemia stem cells also indicated great phenotypic plasticity depending on the stage of tumor growth, tumor microenvironment, and external factors such as stress created by radio-or chemotherapy [2].

The presence of CSCs in solid tumors has been proposed for human cancers including breast [4], brain [5], colon [6], head and 
neck [7], pancreatic [8], prostate [9], ovarian [10,11,12], and skin cancer [13]. Solid tumor stem cells have been defined as "a small subset of cancer cells within a cancer that constitute a reservoir of self-sustaining cells with the exclusive ability to self-renew and to cause the heterogeneous lineages of cancer cells that comprise the tumor" [14]. Several cell surface markers, including CD24, CD44, CD133, CD166, EpCAM, or dye efflux assays have been used to sort populations of putative cancer stem cells from primary tumor cultures or cell suspensions obtained from tumor biopsies. After transplantation into immunodeficient mice, tumors form from several hundred marker-positive cells, whereas for markernegative cells orders of magnitudes higher numbers are needed to achieve the same frequency of tumor formation (for a review: see [15]. Recently, using an improved xenotransplantation technique, a study with human melanoma cells showed tumor formation after inoculation of one tumor cell [16] and thereby an important step towards the proof of CSG existence was made.

For most carcinomas, progression toward malignancy is accompanied by loss of epithelial differentiation and a shift towards a mesenchymal phenotype (EMT) [17]. EMT exacerbates motility and invasiveness of many cell types and is often considered a prerequisite for tumor infiltration and metastasis. EMT is characterized by increased expression of mesenchymal markers (vimentin, thrombospondin, $\mathrm{N}$-cadherin, vitronectin), increased expression of extracellular matrix compounds (collagen IV and fibronectin), decreased expression of epithelial markers (Ecadherin, Occludin, Desmoplakin, and Mucin1), altered location of transcription factors ( $\beta$-catenin, Snail, Slug, Twist, Sox 10, and $\mathrm{NF \kappa B}$ ) and activation of kinases (ERK1, ERK2, and PI3K/AKT) [17]. There are also numerous examples of advanced carcinomas showing that mesenchymal cells can regain characteristics of epithelial cells, a process called mesenchymal to epithelial transition (MET) [18]. Apparently, the epithelial phenotype of cancer cells and the ability to form physical barriers represent a mechanism that restricts access of drugs, antibodies, or immune cells to the sites of tumors. It has been speculated that both EMT and MET involve cells in a metastable hybrid state, e.g. cells with features of both epithelial and mesenchymal cells [19].

Our studies have focused on ovarian cancer. Ovarian cancer is the fourth most common cancer in women and has the highest mortality rate of all cancers of the female reproductive system. Approximately $90 \%$ of human ovarian cancer arises from the ovarian surface epithelium (OSE). The mesodermally derived normal OSE shows epithelial and mesenchymal features, characterized by the expression of both keratin and vimentin [20]. Interestingly, only low levels of E-cadherin are prominent in OSE cells [21] and its expression is restricted to inclusion cysts and deep clefts, remarkably to areas where early malignant events are believed to occur [22]. The integrity of OSE layers is primarily maintained by $\mathrm{N}$-cadherin, which further highlights the epithelial/ mesenchymal phenotype in this tissue [23,24]. It is thought that OSE cells adapt to changes in the cellular microenvironment by transitions between epithelial and mesenchymal stages [20]. Such abilities are usually restricted to immature, regenerating, or neoplastic epithelia and therefore render a unique phenotypic plasticity. It is thought that this plasticity lies at the origin of ovarian cancer. Notably, ovarian carcinomas show a unique feature when compared to other epithelial derived cancers. Whereas the latter are characterized by the loss of epithelial properties during tumor progression, elevated expression of Ecadherin is observed for primary neoplastic ovarian epithelia [25]. However, this initial shift towards a more differentiated phenotype early in tumor progression appears then to be followed by a reacquisition of mesenchymal features in more advanced ovarian tumors, involving a secondary loss of E-cadherin [26,27,28]. Interestingly, the epithelial/mesenchymal phenotype apparent in OSE cells [29] is also found in the invasive front of colon [30] and breast cancer [31], and in normal epidermal tissue during wound repair [32].

In this study, we provide supporting data for one of the key features of CSC, by demonstrating pluripotency, i.e. the ability to give rise to phenotypically heterogeneous daughter cells. Our data suggest that in ovarian cancer cells these features are intrinsically linked with the phenomena of EMT and MET.

\section{Results}

\section{Primary ovarian cancer cultures contain putative CSCs}

We established 51 ovarian cancer cultures from biopsies/ascites of grade III and IV carcinomas (Table S1). After digestion of tumor biopsies with collagenase and trypsin, cell suspensions were cultured in Mammary Epithelial Basal Medium supplemented with EGF, insulin, hydrocortisone, bovine pituitary extract (MEGM) and 1-2\% FBS for up to 5 days. In order to confirm their tumorigenic potential and to eliminate fibroblasts and leukocytes, primary cells were injected into the mammary fat pad of immunodeficient SCID-beige (C.B-Igh-1b/GbmsTacPrkdcscid-Lystbg N7) mice. Nine primary cultures formed xenograft tumors after transplantation of $1 \times 10^{6}$ cells (see Table $\mathrm{S} 1$ ). Xenografts were then excised, digested with proteases and cultured in MEGM with 10\% FBS. For one culture, secondary and tertiary xenografting was performed. Sections and suspensions of original biopsies were named ovc-biopsy, ovc805-biopsy, etc; primary cultures derived from patient biopsies were named ovc316-PC, ovc805-PC, etc; sections or tumor suspensions from xenograft tumors derived from primary cultures were named ovc316-X, ovc805-X, etc; cultures derived from xenografts were named ovc316-XC, ovc805-XC, etc.

Cultures contained different cell types, with clearly distinguishable subsets expressing different cancer markers (e.g. CA-125 or CEA), which was reminiscent of the heterogeneity of tumor cells seen from analysis of sections of the original tumor or the tumor xenograft (Figure 1A, left three panels). Notably, tumor cell heterogeneity was less pronounced in established ovarian cancer cell lines such as SKOV3-ipl (Figure 1A, right panel).

Considering the phenotypic heterogeneity of ovarian cancer, the goal of our study was to isolate different cell subsets of primary ovarian cancer cultures and test them for parameters that have been associated with cancer stem cells, including proliferation, pluripotency, and tumorigenicity. Light microscopy analysis of xenograft cultures (e.g. ovc316-XC) revealed characteristic epithelial subsets that contained polymorphic cells, which also expressed large amounts of the extracellular matrix protein laminin at the interphase to surrounding non-epithelial cells. In culture the epithelial cellular subsets showed higher resistance to trypsin treatment (Figure 1B). We separated the cells from early passages $(p<6)$ into two fractions based on trypsin resistance, and tested their tumorigenicity in SCID-beige mice, but no difference in tumor forming ability was observed (Figure 1B, right panel).

As done previously in an earlier study that analyzed the cellular resistance to oncolytic adenoviruses [33], we established 100 clonal cell cultures derived from early passage ovc316-XC cells. Clones were expanded and analyzed for human-specific and cancer markers (to exclude the presence of mouse stromal cells) as well as epithelial and mesenchymal markers (Figure 1C). A total of 20\% of the resulting cultures were restricted to an epithelial phenotype (Ecadherin positive; "epithelial clone"), whereas 19\% were mesenchymal (laminin positive, "mesenchymal clone"). The remaining 
A

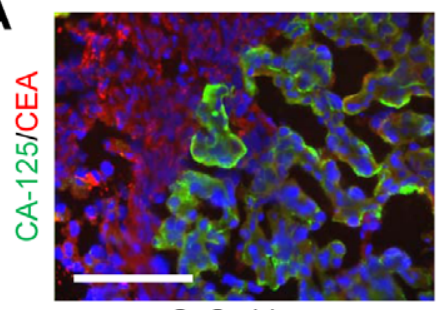

OvCa biopsy

B

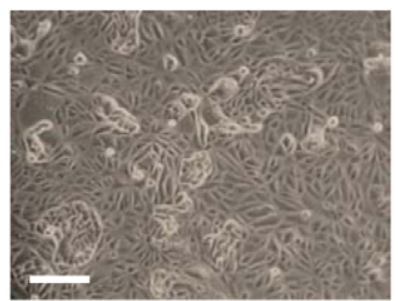

C
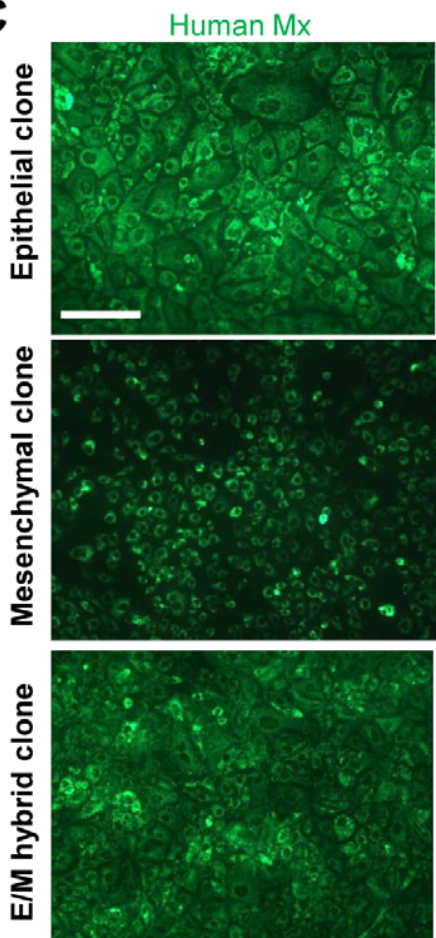

D

E

E

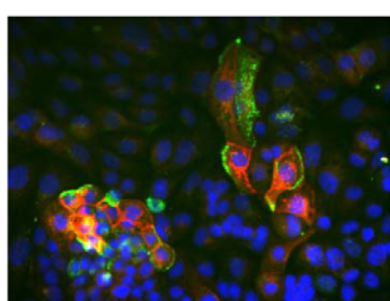

OvCa primary culture

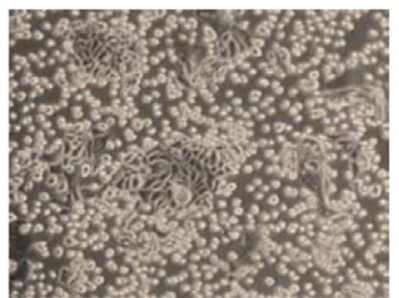

CEA
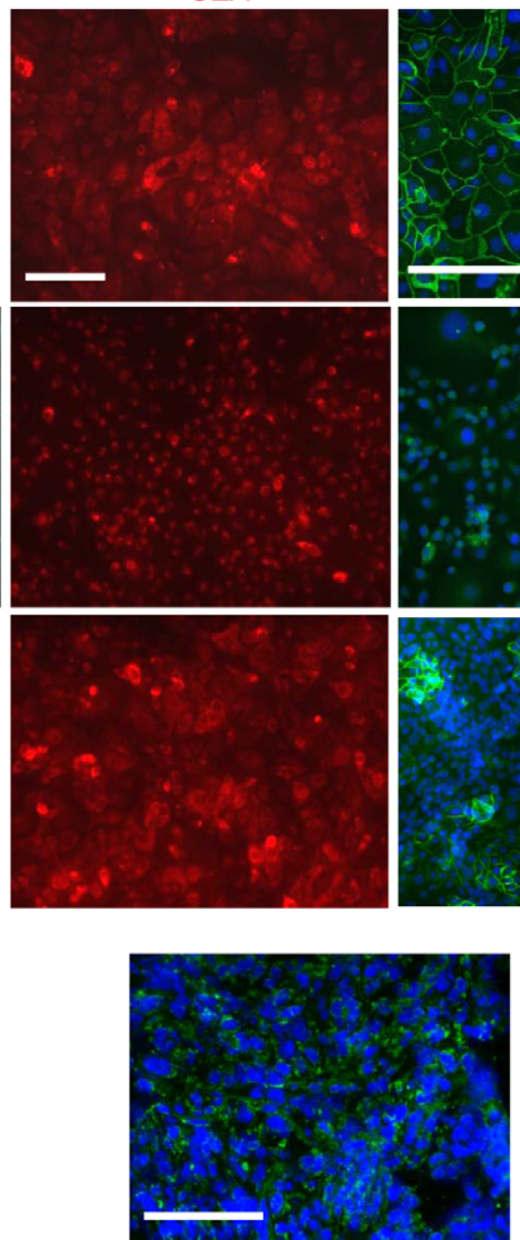

Human Mx

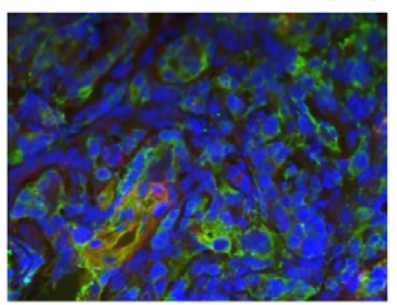

AE1/3/CEA

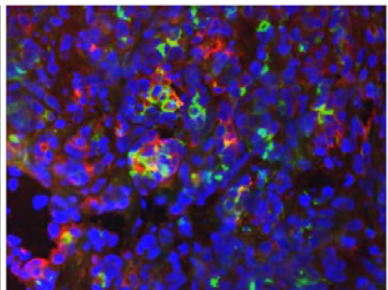

OvCa xenograft

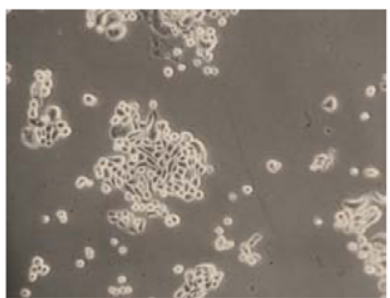

E-cadherin
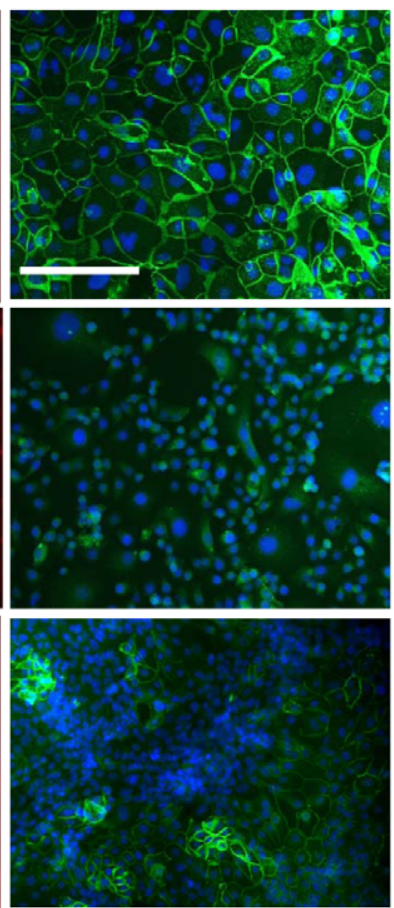

$\mathbf{F}$
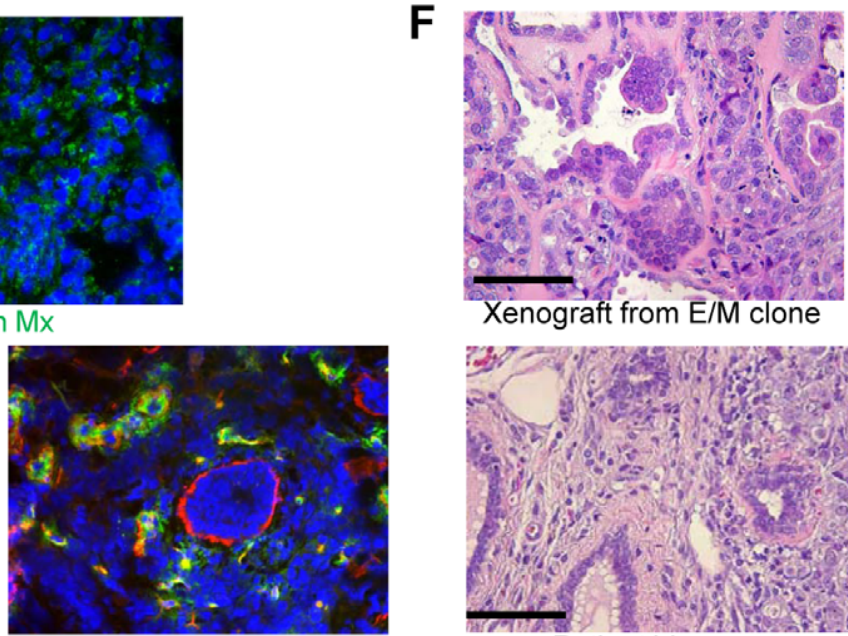

mCD31/Laminin

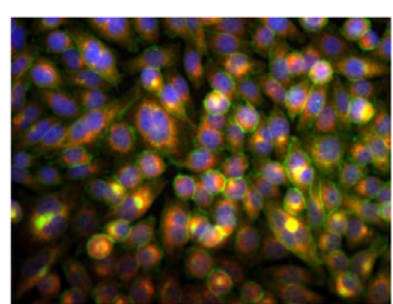

SKOV3-ip1 culture

\section{Tumor formation}

Injected cells TR TS

$100 \quad 2 / 5 \quad 3 / 5$

$1,000 \quad 5 / 5 \quad 5 / 5$

$10^{4} \quad 3 / 3 \quad 3 / 3$

$10^{5} \quad 2 / 2 \quad 2 / 2$

Laminin
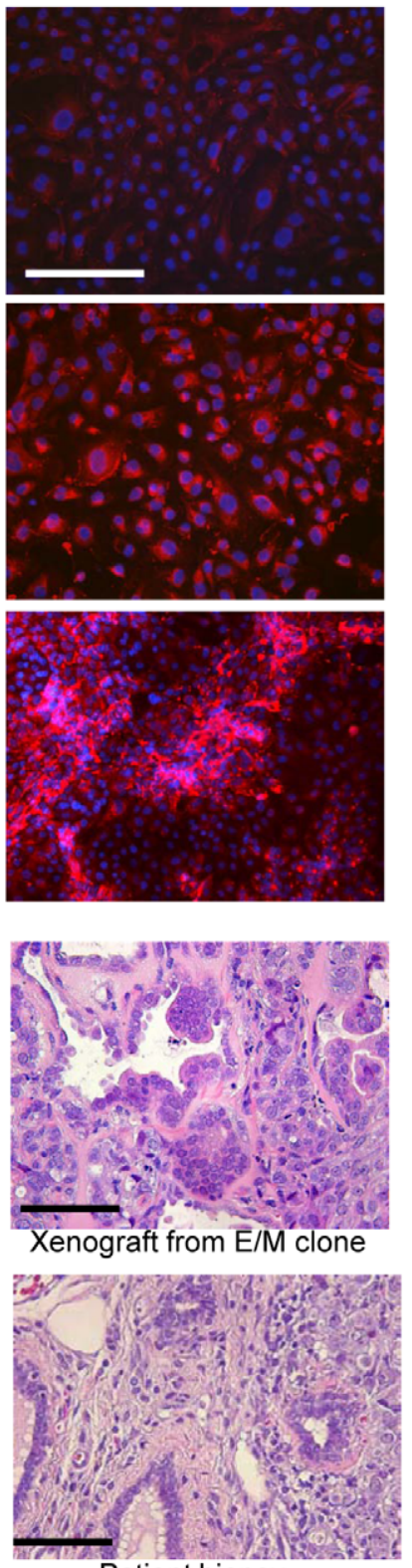

Patient biopsy 
Figure 1. Primary ovarian cancer cultures are heterogeneous and contain putative CSCs. A) Tumor biopsies and primary cultures stain positive for ovarian cancer markers CA-125 (green) and CEA (red) and show higher heterogeneity than the established cell line SKOV3-ip1. Shown are ovc316-biospy, ovc316-PC, and ovc316-X. Analysis of ovc1208-biopsy, ovc1208-PC, ovc0117-biopsy, ovc0117-PC, ovc100506-biopsy, and ovc100506PC revealed the same heterogeneity. B) Light microscopy of ovarian cancer culture ovc316-XC. The culture contains two distinct populations with regards to trypsin sensitivity. Left panel: an early passage culture untreated (left), after 10 min trypsin treatment (center), and after trypsin-sensitive cells were removed (right). Right panel: Tumor formation after transplantation of trypsin-resistant (TR) and trypsin-sensitive (TS) cells into SCID-beige mice. Tumor formation was evaluated 3 months after inoculation. TIC TR: 1/185, TIC TS: 1/109. Chi-square $=0.0524$. C) Immunofluorescence analysis for a human-specific mitochondrial (Mx) marker, the cancer marker CEA, the epithelial marker E-cadherin, and the mesenchymal marker laminin in clonal cultures derived from ovc316-XC. Clonal cultures contain human cancer cells with either epithelial (upper panel), mesenchymal (center) or both phenotypes (E/M hybrid clone, lower). D) Tumor-forming abilities after transplantation of $10^{5} \mathrm{E}$, $\mathrm{M}$, or E/M cells into SCID-beige mice. Tumor formation was evaluated 4 months after inoculation. E) Xenograft tumors derived from E/M hybrid clones. The human origin of tumor cells is shown by staining for a human specific mitochondria marker (green). Staining for the epithelial antigen AE1/3 and the tumor antigen CEA reveals phenotypic heterogeneity in tumors that are derived from clonal E/M cultures. Laminin-expression is largely restricted to vascularized regions. F) H\&E staining of a xenograft derived from an ovc316-XC E/M clone and from a patient biopsy (ovc316-biopsy) showing that xenografts from resemble the histology of human tumors in situ. The scale bar is $40 \mu \mathrm{m}$.

doi:10.1371/journal.pone.0016186.g001

$61 \%$ of clonal cultures contained both epithelial and mesenchymal cells, in addition to cells that were positive for both epithelial and mesenchymal markers (Figure 1G). We called these cells epithelial/mesenchymal (E/M) hybrid cells. Clonal epithelial and mesenchymal cultures had limited long-term proliferative potential (20-25 passages mesenchymal, 20-40 passages epithelial cultures respectively). Notably, during passaging, cells in one of the 20 epithelial clones lost membrane E-cadherin and claudin 7 and acquired the mesenchymal transcription variant of p120 catenin [33], indicating that it underwent an EMT (Figure S1).

Importantly, only cultures containing $\mathrm{E} / \mathrm{M}$ cells were able to form tumors in SCID-beige mice within 4 months when $10^{5}$ cells (passage 6) were injected (Figure 1D). Tumors displayed phenotypic heterogeneity, contained tumor stroma and were vascularized (Figure 1E). Overall, histology of tumors derived from transplanted clonal E/M cells was similar to that of the patient tumor (Figure 1F). Serial transplantation of cells derived from these tumors also gave rise to new tumors (data not shown). Significantly, this study shows that a single cell can form a clone that is subsequently able to form a heterogeneous tumor. This indicates that the original cell was a potential cancer stem cell, with the ability to differentiate, selfrenew, and form a tumor. Taken together, these data show that primary ovarian cancer cultures are phenotypically heterogenous and that tumor-initiating cells appear to have traits of mesenchymal and epithelial (E/M) cells.

\section{Cells at the periphery of trypsin-resistant subsets contain epithelial-mesenchymal hybrid (E/M) cells that co-stain with stem cell markers \\ Having found a potential link between tumorigenic cancer stem} cell-like and epithelial/mesenchymal traits on clonal cultures from ovc316-XC, we performed immunofluorescence analyses of the primary ovarian cancer cultures (derived from biopsies or xenografts) with a number of epithelial and mesenchymal markers (Figure 2). We focused our analysis on cells that were isolated from xenografts and had just (passage $0 / 1$ ) or recently (passages 6-10) adapted to tissue culture, and contained large proportions of trypsin-resistant subsets. These subsets stained positive for epithelial markers E-cadherin, claudin7 and EpCAM on lateral cell membranes (Figures 2A, B). Cells surrounding epithelial subsets were negative for these markers on their lateral membranes and stained for mesenchymal proteins vimentin and laminin. Further analysis for E-cadherin revealed phenotypic diversity within ovc316-XC cultures. Two types of cells that localized E-cadherin to their membranes were observed, membrane E-cadherin ${ }^{\text {high }}$ and membrane E-cadherin ${ }^{\text {low }}$ (Figure 2A, lower panel, insert \#2 and $3 \#)$. A third type of cells adjacent to membrane E-cadherin ${ }^{\text {high }}$ cells contained clearly detectable E-cadherin in the cytoplasm/nucleus
(Figure 2A, lower panel, insert \#2). Cytoplasmic E-cadherin ${ }^{\text {high }}$ cells also stained positive for mesenchymal cell markers such as laminin as well as caldesmon-1 (a myeloid marker), the endothelial/endothelial progenitor markers CD31, and VCAM-1 (Figure $\mathrm{S} 2 \mathrm{~A})$. E-cadherin ${ }^{\text {high }} \mathrm{E} / \mathrm{M}$-cells also expressed high levels of the angiopoietin receptor Tie2 (Figure S2A, right panels). Notably, Tie2 is a marker for hematopoietic stem cells that is also found on a series of epithelial tumors [34,35].

Cultures at passage $0 / 1$ generally showed higher overall expression of epithelial and mesenchymal markers than cultures in passages 6-10 and formed 3 dimensional cell conglomerates/ spheres containing $\mathrm{E} / \mathrm{M}$ hybrid cells in highly proliferative areas (Figure 2B). The E/M hybrid stage of cells (within spheres) was confirmed by double staining with other epithelial markers (EpCAM, claudin7) and mesenchymal markers (N-cadherin, vimentin). Furthermore, spheres stained for EpCAM and the mesenchymal stem cell marker CD44. Notably, most cells stained for EpCAM, GD44, and vimentin (Figure 2B), suggesting that EpCAM/CD44 signals underestimate the phenotypic diversity within early passage ovarian cancer cells. The best discrimination between different subsets was achieved with E-cadherin in combination with a mesenchymal marker or CD44. Subsequently we used this marker combination to characterize most of the ensuing experiments. When analyzed for E-cadherin and the putative cancer stem marker CD133, two subfractions of CD133 positive cells become apparent $\mathrm{CD} 133^{+} / \mathrm{E}$-cadherin ${ }^{\text {high }}$ and CD $133^{+} /$E-cadherin ${ }^{\text {low }}$ cells (Figure $2 \mathrm{C}$ ). This observation further supports the role of E-cadherin as a potential discriminatory marker for cancer cell subsets. Cells within the E/M cell population (particularly E-cadherin ${ }^{\text {low }}$ cells) also expressed other markers that are characteristic of stem cells, including Nanog, Oct 4, and Sox2 (Figure S2B). E/M cells, particularly cells in spheres, were also highly positive for the EMT inducers Snail, Twist and NGAL (Figure 2D). Furthermore, we also found that cells that were low in membrane-claudin 7 predominantly localize beta-catenin to the cytoplasm/nucleus (Figure S2C). Transition of beta-catenin from the cell membrane to the nucleus is an early event in EMT.

Overall, immunofluorescence studies indicate the existence of two $\mathrm{CD}_{133^{+}}$fractions; i) membrane E-cadherin ${ }^{\text {high }}$ and ii) cytoplasmic E-cadherin ${ }^{\text {high }} /$ membrane E-cadherin ${ }^{\text {low }}$ cells. Cytoplasmic E-cadherin ${ }^{\text {high }} /$ membrane E-cadherin ${ }^{\text {low }}$ cells carry traits of other cell lineages and therefore, most likely, represent primitive progenitor cells or stem cells.

\section{Change of phenotype, EMT and differentiation in vitro: flow cytometry studies}

To quantify numbers of cells with epithelial and mesenchymal phenotypes in cultured cells, we employed flow cytometry and 
A
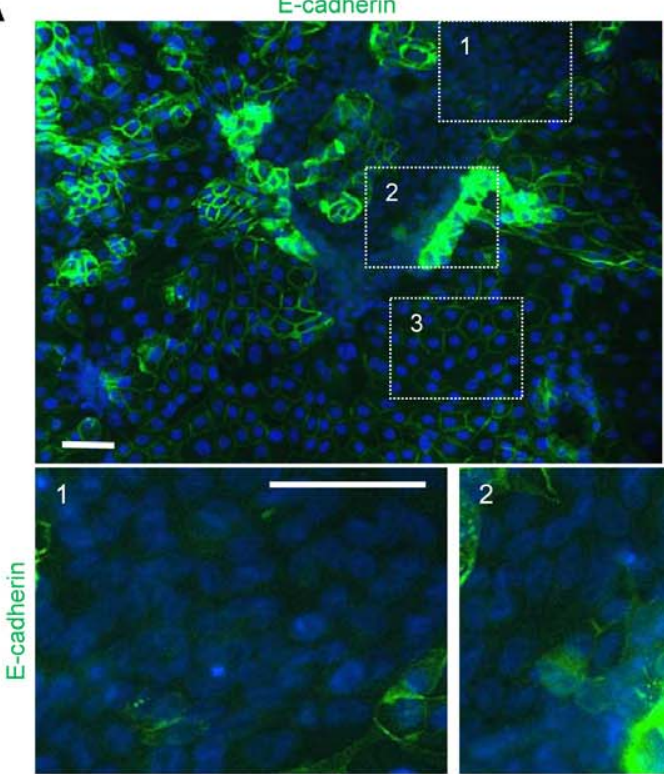

B

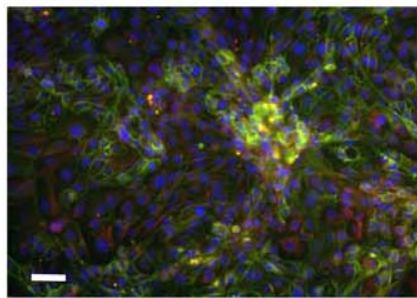

EpCAM / Vimentin

C

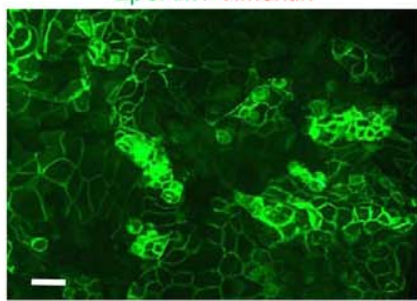

E-cadherin

D

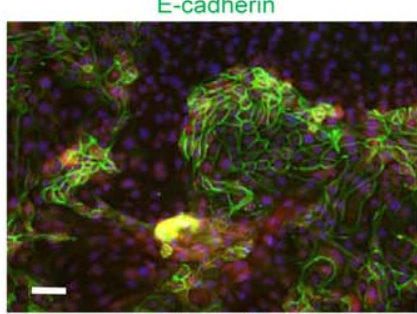

E-cadherin / Snail
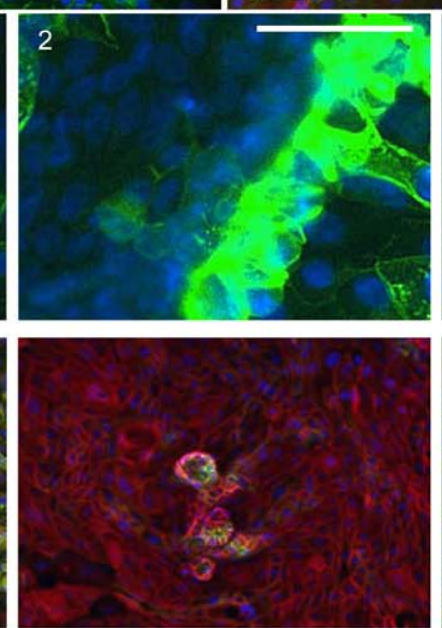

Claudin 7 / CD44

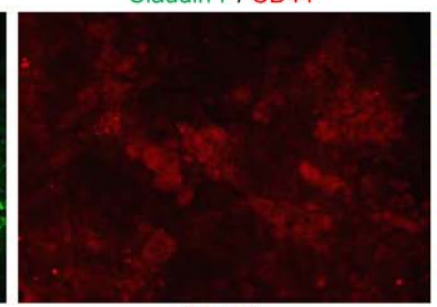

CD133

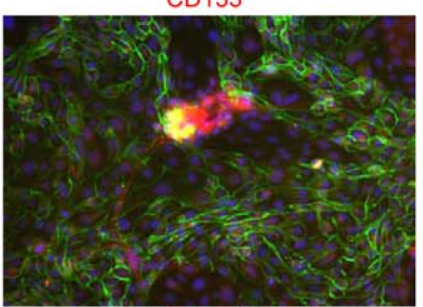

E-cadherin / Twist
E-cadherin / Laminin
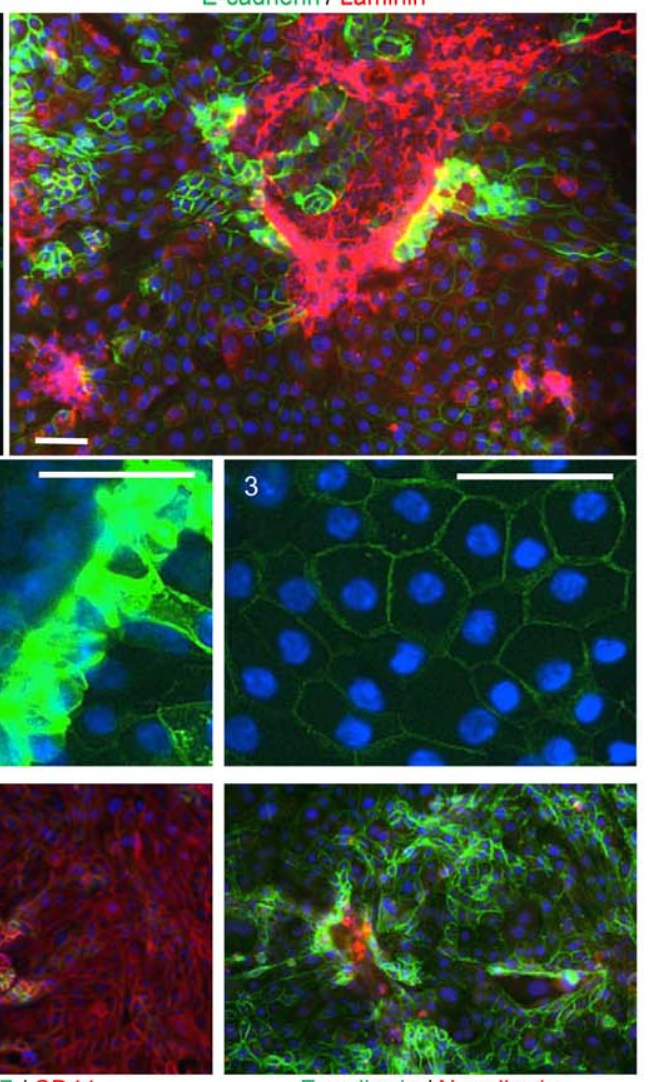

E-cadherin / N-cadherin

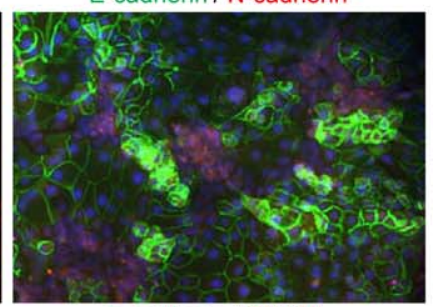

E-cadherin / CD133

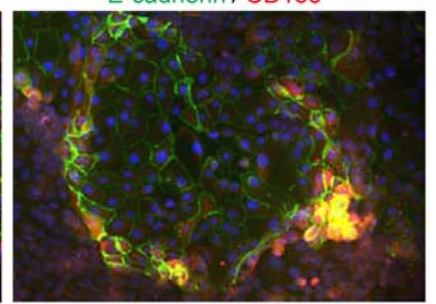

E-cadherin / NGAL

Figure 2. Tumorigenic primary ovarian cancer cultures contain epithelial-mesenchymal hybrid (E/M) cells that co-stain with stem cell markers. A) Analysis of E-cadherin (green) and Laminin (red) in ovarian cancer cultures. Magnification of marked areas is shown at the bottom: A1) E-cadherin ${ }^{\text {negative }}$ cells express laminin. A2) Epithelial/mesenchymal (E/M) hybrid cells: E-cadherin ${ }^{\text {low }}$ cells show mainly cytoplasmic localization of E-cadherin and high expression of laminin. E-cadherin ${ }^{\text {high }}$ cells contain elevated membrane E-cadherin levels and lower amounts of laminin. A3) Ecadherin $^{\text {positive }}$ cells have an increased cell size and maintain lower levels of clearly membrane-localized E-cadherin than E-cadherin ${ }^{\text {high }}$ cells. Laminin expression is almost absent in E-cadherin ${ }^{\text {positive }}$ cells (upper right panel). B) Analysis for additional epithelial (green) and mesenchymal (red) markers confirms the existence of E/M hybrid cells in ovc316-XC cultures. Epithelial marker high cells are in close proximity to mesenchymal marker ${ }^{\text {high }}$ cells and stain double positive in areas that contain spheres. In the left and middle panel, note that all cells are positive for vimentin and CD44. C) CD133 marks areas that contain E-cadherin ${ }^{\text {high }}$ and E-cadherin ${ }^{\text {low }}$ cells. D) E-cadherin ${ }^{\text {high }}$ and E-cadherin low cells show strong co-labeling with the EMT-inducers

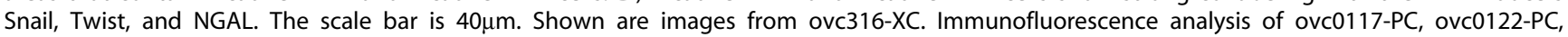
ovc100506-XC, and ovc100728-XC revealed similar results.

doi:10.1371/journal.pone.0016186.g002

started by monitoring cells for the epithelial marker EpCAM as well as monitoring for vimentin or CD44 marking cells with mesenchymal attributes. Furthermore, to delineate phenotypic changes overtime such as initiation of EMT, we analyzed different passages of ovc316-XC cells (Figure 3). These studies revealed a number of interesting observations. i) In tumor cell suspensions 
that were freshly isolated from xenografts, the majority of cells were either E/M cells $\left(\mathrm{EpCAM}^{\text {high }} /\right.$ Vimentin ${ }^{\text {high }}, \mathrm{EpCAM}^{\text {high }}$ / $\left.\mathrm{CD} 44^{\text {high }}\right)$ or E-cells $\left(\right.$ EpCAM $^{\text {high }} /$ Vimentin $^{\text {low }}$, EpCAM $^{\text {high }} /$ CD $44^{\text {low }}$, however, at passage 1 only $\mathrm{E} / \mathrm{M}$ cells could be detected, indicating that the majority of cells obtained from xenografts that adapt to tissue culture are E/M (Figure 3A). This implies that, even at early passage, cultures do not adequately reflect the cellular composition of the tumor in situ. Passage 1 contained EpCAM ${ }^{\text {high }} / \mathrm{CD} 44^{\text {high }} /$ Vimentin ${ }^{\text {high }}$ and EpCAM ${ }^{\text {high }}$ / CD $44^{\text {low }} /$ Vimentin ${ }^{\text {low }}$ cells. ii) Importantly during culture of cells in MEGM containing growth factors/FBS (see passages 1, 5, 7, 20), both the EpCAM ${ }^{\text {high }} / \mathrm{CD} 44^{\text {high }} /$ Vimentin high or EpCAM ${ }^{\text {high }}$ / $\mathrm{CD} 44^{\text {low }} /$ Vimentin ${ }^{\text {low }}$ cell types disappeared and were replaced by EpCAM $^{\text {low }} / \mathrm{CD} 44^{\text {high }} /$ Vimentin ${ }^{\text {high }}$ cells. This demonstrates that $\mathrm{E} / \mathrm{M}$ cells differentiate into mesenchymal cells in vitro in an EMT-like manner. iii) The majority of $\mathrm{CD} 133^{+}$cells are E/M hybrid cells. After passaging in culture ovc316-XC cells rapidly lose CD133 expression concomitantly with the loss of epithelial features.

We also found that for a number of passages starvation can stall differentiation and the loss of the epithelial phenotype, while levels of CD133 slightly decrease during this process (Figure 3B). Overall, we found that primary ovarian cancer cultures show more sphere formation when cultured without growth factors (Figure S3).

Having identified E-cadherin as a marker capable of differentiating cellular subsets, we repeated flow cytometry analyses with E-cadherin (Figure S3). Differentiation was also reflected by a decrease in levels of E-cadherin and laminin after passaging. Whereas low passage cultures contained high numbers of spheres, E-cadherin ${ }^{\text {high }}$ cells, and excessive amounts of laminin, high passage cells showed markedly reduced sphere growth and low levels of these proteins while cell size increased (Figure 3C). This was also confirmed in flow cytometry studies of passages 1, 3, and 7 (Figures S3A-C). These studies show that the mesenchymal (Ecadherin $^{\text {negative/low }}$ sub-fraction increases during passaging and concomitant EMT. CD $133^{+}$cells were highly positive for CD44 (Figure S3A). We also analyzed membrane Tie2 in correlation to E-cadherin (Figure S3B). By immunofluorescence analysis, Tie2 cells have an epithelial phenotype and are lower in CD44 than $\mathrm{CD}_{133^{+}}$cells. Notably, a correlation between E/M phenotype, CD133/CD44-positivity, and tumorigenicity is also supported by flow cytometry analysis of clonal cultures (Figure S3G). Only E/M clones contained considerable amounts of $\mathrm{CD}_{133^{+}}$cells with elevated expression of CD44 (and as shown earlier, only E/M clones formed tumors). The loss of "stem cell" features during passaging is also reflected by reduction of the fraction of side population (SP) cells from $7.8 \pm 0.5 \%$ at passage 3 ) to $2.1 \pm 0.3 \%$ at passage 18 (Figure 3G). The SP cell phenotype has been associated with cancer stem cells in previous studies of ovarian cancer [36]. Finally the loss of $\mathrm{CD}_{133^{+}}$and $\mathrm{E} / \mathrm{M}$ cells correlated with a reduced ability to form tumors (Figure 3D).

Overall, we observed a striking difference of phenotypes between cells in vivo and in vitro. Cells that adapted to tissue culture were $\mathrm{CD}_{133^{+}} \mathrm{E} / \mathrm{M}$ cells. After passaging E/M cells differentiate into mesenchymal cells in an EMT like manner. This process is accompanied by a reduction of tumorigenicity.

\section{Presence of E/M cell subsets in situ}

Taking into consideration that ovarian cancer cultures, particularly at late passages, only poorly reflect the phenotype of tumors in situ, we focused our immunofluorescence and flow cytometry analyses on sections of tumor biopsies or xenografts, or cell suspensions obtained by collagenase digestion of tumors (Figure 4). Immunofluorescence analyses of sections from xenografts harvested at week 10 after tumor cell transplantation (Figure 4) or sections of patient biopsies (Table S1, Figure S4) showed that tumors in situ have clusters of E/M cells $\left(\mathrm{EpCAM}^{+}\right.$/ vimentin $^{+}$) as well as clusters of epithelial cells (E-cadherin ${ }^{+} /$ Vimentin $^{-}$) (Figure 4A). In xenografts, nests of E/M and epithelial cells were surrounded by layers of laminin. We also observed costaining of E-cadherin and Tie2 (Figure 4B). CD133 $3^{\text {high }}$ cells (blue) are Tie $2^{\text {low }}$ and E-cadherin ${ }^{\text {low }}$ (Figure $4 \mathrm{~B}$, lower panel). An interesting pattern was observed when double staining with Ecadherin and CD133 as CD133 positive cells were found at the tumor periphery, in areas of active tumor growth (Figure S5A). Notably not all $\mathrm{CD} 133^{+}$cells were E/M cells. Within CD $133^{+}$ cells, we found two subsets of $\mathrm{E} / \mathrm{M}$ cells as described earlier for the in vitro studies (Figure 4C, larger magnification in Figure S5B). Interestingly the CD $133^{\text {high }} /$ membrane E-cadherin ${ }^{\text {low }}$ subset in situ showed the presence of E-cadherin within cytoplasmic vesicles more apparently than in vitro. The results obtained using xenograft tumors were representative for staining of tumor sections from nine different patients (Table S1, Figure S4).

Immunofluorescence analyses of tumors indicate the presence of two E/M cell fractions: CD133 $3^{\text {high }} /$ membrane E-cadherin ${ }^{\text {low }} /$ cytoplasmic E-cadherin high $/ \mathrm{Tie} 2^{\text {negative/low }}$ and CD133 $3^{\text {intermediate }}$ / membrane E-cadherin ${ }^{\text {high }} /$ cytoplasmic E-cadherin ${ }^{\text {negative }} / \mathrm{Tie} 2^{\text {high }}$. These immunohistological findings are supported by triple-color flow cytometry analysis of ovc316-X xenografts for epithelial markers (x-axis), mesenchymal features (y-axis), and for the cancer stem cell marker CD133 (histogram plots) (Figures 4D-F). Xenografts contain epithelial cells, epithelial/mesenchymal (E/M) hybrid cells, and cells that are negative for all markers. CD $133^{+}$cells are almost exclusively in an E/M hybrid stage based on EpCAM/ CD44 analysis. CD $133^{\text {high }}$ cells are EpCAM ${ }^{\text {high }}, \mathrm{CD} 44^{\text {high }}$ and vimentin $^{\text {low }}$ (Figure 4D). As in earlier studies, replacement of EpCAM with E-cadherin in analyses reveals higher diversity within xenografts (Figure 4E). CD44 ${ }^{\text {high }}$ cells are E-cadherin ${ }^{\text {low/intermediate }}$. $\mathrm{CD} 133^{+}$cells are divided into two clear sub-fractions. Fraction 1: Ecadherin $^{\text {low/intermediate }} / \mathrm{CD} 44^{\text {high }}$ and fraction 2: E-cadherin ${ }^{\text {high }}$ / CD44 $4^{\text {intermediate }}$ CD133 $3^{\text {high }}$ cells are E-cadherin ${ }^{\text {low/intermediate }}$, CD $44^{\text {high }}$ and vimentin ${ }^{\text {low }}$. Therefore CD44 and vimentin positivity is inversely correlated. Tie2 marks cells that are E-cadherin high/ CD44 $4^{\text {intermediate }}$ and predominantly positive for vimentin (Figure 4F). Tie ${ }^{-}$cells are highly depleted for CD133 sub-fraction 2 and for E-cadherin ${ }^{\text {high }}$ /vimentin ${ }^{\text {high }}$ cells.

Because the phenotype of cultured ovarian cancer cells only poorly reflects that of the tumor in situ, analysis of cell suspensions of xenograft tumors without culturing is important. These studies confirmed and extended our key conclusion from in vitro studies, namely the existence of different subsets within $\mathrm{CD} 133^{+}$cells: CD $133^{\text {high }} /$ membrane E-cadherin low/intermediate/cytoplasmic Ecadherin $^{\text {high }} / \mathrm{Tie}^{\text {negative }}$ and CD $133^{\text {intermediate }} / \mathrm{membrane}$ E-cadherin $^{\text {higgh }} /$ cytoplasmic E-cadherin $^{\text {low }} / \mathrm{Tie}^{\text {positive }}$.

Having identified several different cellular subsets in suspensions from xenograft tumors, we attempted to isolate different fractions using MACS or FACS for subsequent tumorigenicity and pluripotency studies. Because of significant overlaps of cell populations based on epithelial (E-cadherin/EpCAM) or mesenchymal markers (CD44/vimentin), we decided to use an indirect approach to isolate $\mathrm{E} / \mathrm{M}$ cell subfractions. As shown above, the vast majority of E/M cells were CD133-postive. We therefore isolated CD133-positive and CD133-negative cells using antiCD133 conjugated magnetic bead columns (Figure 5A) and cell purity and viability was validated by flow cytometry. The "CD133", fraction contained 92.2\% CD133-positive cells, whereas the CD133-"negative" fraction contained $5.4 \%$ of CD133-positive cells. Tumorigenicity of $\mathrm{CD}_{133^{+}}$and $\mathrm{CD} 133^{-}$ 
A
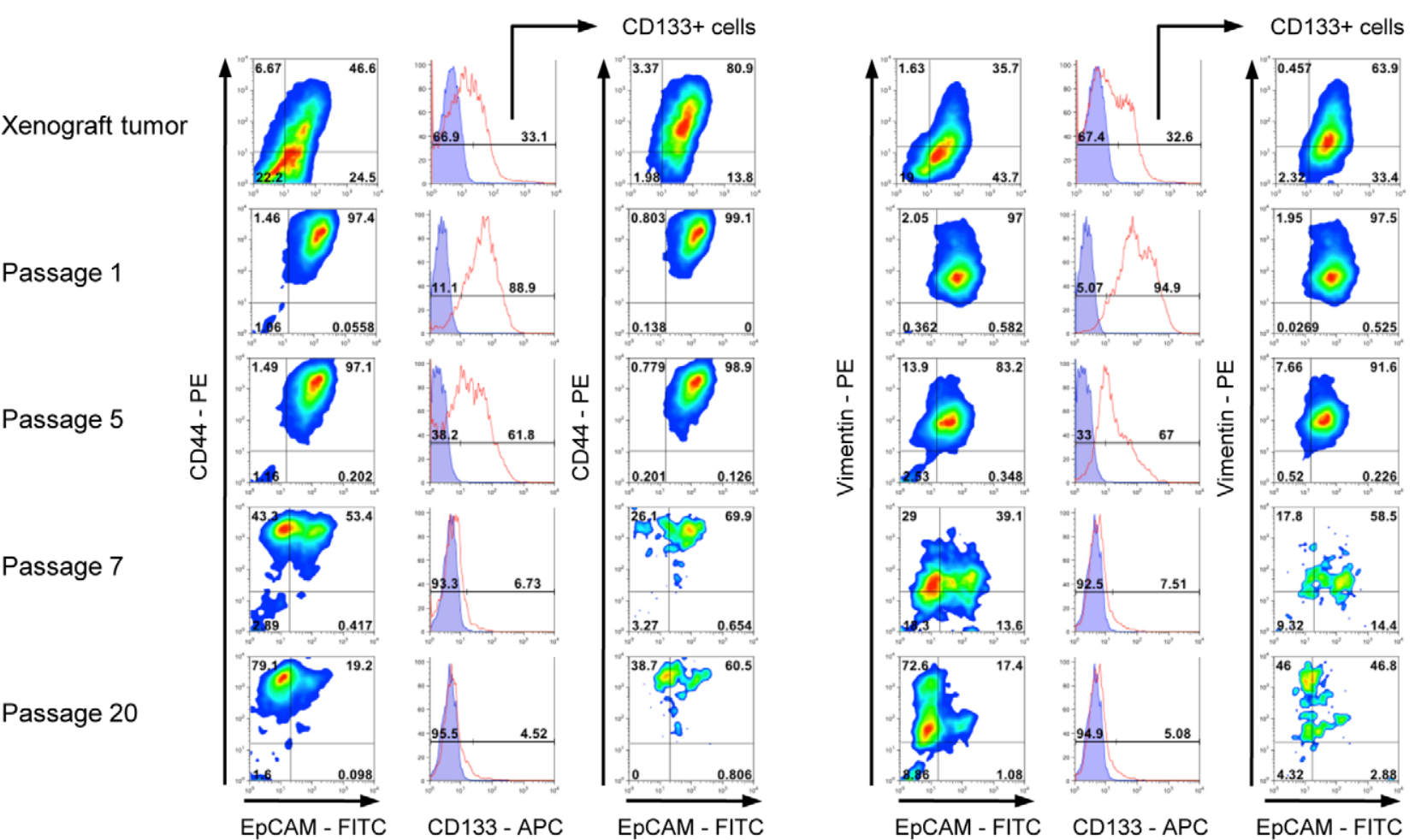

B

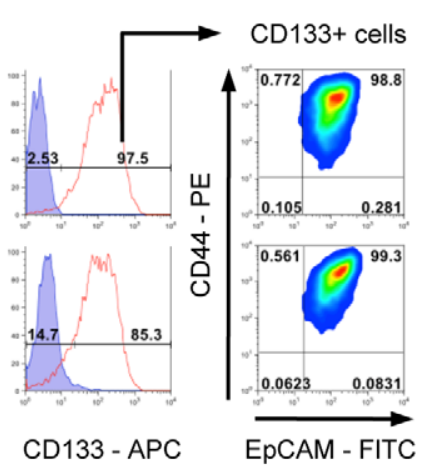

C

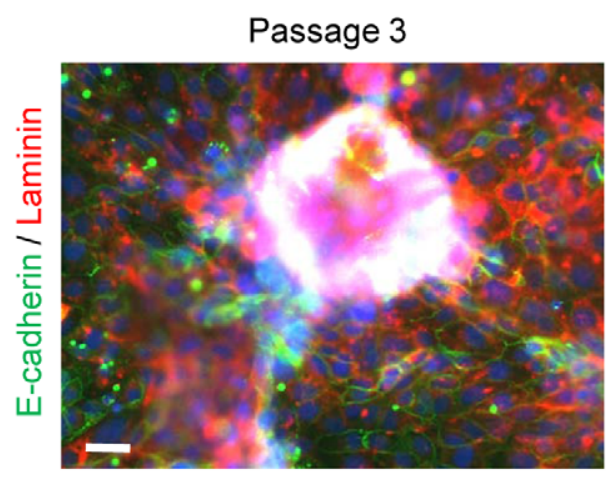

SP cells:

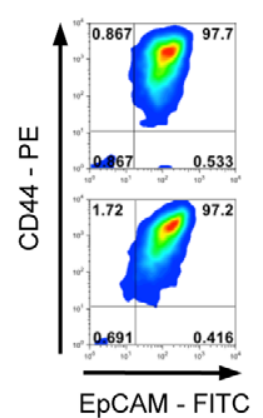

CD133 - APC
EpCAM - FITC
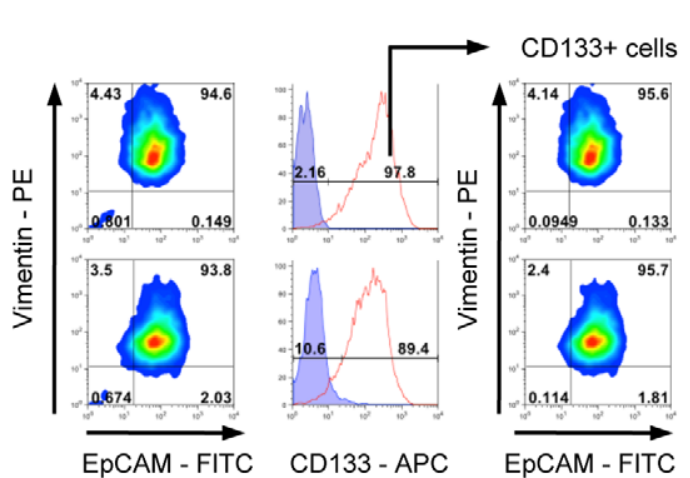
passages. Percentage of side population (SP) positive cells are shown below. The scale bar is $40 \mu \mathrm{m}$. D) Tumor formation after transplantation of ovc316-XC passage 3 and 18 cells into SCID-beige mice (evaluated 4 months after inoculation). TIC p3: 1/110, TIC p18: 1/744. Chi-square: 0.245. doi:10.1371/journal.pone.0016186.g003

fractions was analyzed in SCID-beige mice. Three out of 10 mice formed tumors after transplantation with $10 \mathrm{CD} 133^{+}$cells while 100 fold more CD133- cells were needed to achieve tumor formation in 5 out of 10 mice (Figure 4A, lower panel). This indicates that the $\mathrm{CD}_{13} 3^{+}$cell fraction is enriched for tumorforming cells. Histology of $\mathrm{CD} 133^{+}$and $\mathrm{CD} 133^{-}$derived tumors was identical, and tumors contained E/M (E-cadherin/laminin) positive cells and were vascularized (Figure S6A). This could be as a result of tumors from the "CD133" " population being derived from the 5.4\% contaminating CD133-positive cells. Alternatively, "CD133" cells might be tumor-initiating, but at a lower efficiency. Co-staining for the proliferation marker Ki-67 revealed that both $\mathrm{CD} 133^{+}$and $\mathrm{CD} 133^{-}$cells contain similar numbers of $\mathrm{Ki}-67$ positive cells (Figure $\mathrm{S} 6 \mathrm{~B}$ ).

Figure $4 \mathrm{~F}$ shows that a significant subset of $\mathrm{E} / \mathrm{M}$ cells were positive for Tie2 $37 \%$ of $\mathrm{CD} 44^{+} / \mathrm{E}$-cadherin ${ }^{+}$cells or $29.3 \%$ of Vimentin $^{+} /$E-cadherin ${ }^{+}$cells) and that the vast majority of Tie2positive cells were E/M cells $\left(90.7 \%\right.$ of $\mathrm{CD} 44^{+} / \mathrm{E}$-cadherin ${ }^{+}$and $73.6 \%$ of vimentin ${ }^{+} / \mathrm{E}$-cadherin ${ }^{+}$cells). Instrumental for a separation of different E-cadherin fractions was the finding that the low membrane E-cadherin levels correlated with low/absent Tie2 expression. Column-isolated $\mathrm{CD}_{13} 3^{+}$cells were therefore further subdivided into $\mathrm{Tie} 2^{+}$and $\mathrm{Tie} 2^{-}$fractions using FACS (Figure 5B). When transplanted into mice, tumor-forming ability was clearly localized to $\mathrm{CD} 133^{+} / \mathrm{Tie}^{-}$cells (Figure 5B, lower panel). Immunofluorescence analysis of tumors derived from transplanted $\mathrm{CD}_{133^{+}} / \mathrm{Tie}^{-}$cells demonstrated that $\sim 50 \%$ of tumor cells were positive for Tie2 and expressed membrane Ecadherin. Tie2 negative cells had cytoplasmic, punctuated Ecadherin staining. This indicates that i) $\mathrm{Tie} 2^{-} /$membrane Ecadherin ${ }^{\text {low }}$ cells transdifferentiate in vivo into epithelial Tie $2^{+} / \mathrm{E}-$ cadherin $^{\text {high }}$ cells (through MET) and ii) primitive Tie2 ${ }^{-}$/ cytoplasmic E-cadherin cells (i.e. potential cancer stem cells) are maintained during tumor growth.

To consolidate these findings we performed studies with tumor cells directly isolated from human ovarian cancer biopsies (see Figures 5D-F). Biopsies were digested with collagenase/dispase and cell suspensions were cultured in a rotating flask for 5 hours to restore receptor expression. Cell suspensions were then subjected to MACS for CD133 and FACS to separate CD133 ${ }^{+} /$Tie $^{-}$and $\mathrm{CD} 33^{+} / \mathrm{Tie}^{+}$cells (Figure 5D). Different numbers of $\mathrm{CD} 133^{+} /$ Tie $2^{-}$and $\mathrm{CD} 133^{+} / \mathrm{Tie}^{+}$cells from biopsies were tested for tumor formation (Figure 5E). Overall, engraftment of cells from biopsies was less efficient than that of cells that had been cultured and xenografted. Importantly, however, no tumor formation was observed after transplantation of $\mathrm{CD} 133^{+} / \mathrm{Tie}^{+}$cells, whereas 2 out of 15 or 8 out of 15 mice developed tumors after transplantation of 100 or $1,000 \mathrm{CD} 133^{+} / \mathrm{Tie}^{-}$cells, respectively. These data indicate that tumor-forming cells are enriched in the fraction of CD $133^{\text {high }} / \mathrm{Tie}^{-}$/surface E-cadherin ${ }^{\text {low/intermediate }}$ cells.

In summary, based on the immunofluorescence and flow cytometry data in vitro and in vivo, we tentatively propose two phenotypically different subsets of $\mathrm{CD} 133^{+} \mathrm{E} / \mathrm{M}$ cells: i) E/M-MP cells (CD133 high/membrane E-cadherin ${ }^{\text {low/intermediate } / \text { cytoplasmic }}$ E-cadherin ${ }^{+} / \mathrm{Tie}^{-}{ }^{-}$). These cells are multipotent, having epithelial, mesenchymal, and possibly other lineage traits. E/M-MP cells are enriched for tumor-forming cells. ii) E/M-E cells (CD133intermediate $/$ membrane E-cadherin $^{\text {high }}$ /cytoplasmic E-cadherin ${ }^{\text {negative }} / \mathrm{Tie}^{+}$). We hypothesize that these cells are epithelial progenitor cells that are less tumorigenic.

\section{Phenotype studies on established ovarian cancer cell lines in vitro and in vivo}

We tested a series of human ovarian cancer cells lines, that are widely used as models for testing new therapeutics (SKOV-3, OVCAR3, and OVCAR5). SKOV-3 and OVCAR5 are tumorigenic while OVAR3 is not under the conditions used in this study. With regards to marker expression, SKOV-3 and OVCAR5 grouped together and both lines expressed high levels of EpCAM and CD44, but were nearly negative for surface CD133 (Figures 6A and $\mathrm{B}$, upper panels). While in vitro the majority of SKOV3 and OVAR5 cells were E-cadherin negative, the vast majority of tumor cells in xenografts expressed high levels of Ecadherin (Figures 6A and B, lower panels). In contrast, a different marker phenotype was found for the non-tumorigenic line OVCAR3 (Figure 6C). While these cells were also high for EpCAM, CD44 levels were lower than in SKOV-3 and OVCAR5. Most OVCAR3 cells were E-cadherin-positive, having a more epithelial phenotype than SKOV3 and OVAR5 cells, which apparently inversely correlated with tumorigenicity.

In agreement with our studies in ovc316-XC cells, we found E/ M hybrid cells (positive for EpCAM and/or E-cadherin, CD44 ${ }^{+}$, and Tie2) in SKOV3 and OVC316-XG cells. We also confirmed that upon transplantation, these cells acquire a more epithelial phenotype, a process reminiscent of MET. In contrast to studies with ovc316-XC cells, the ovarian cancer cell lines were almost completely negative for surface CD133, however contained CD133 in cytoplasmic vesicles (Figure 6D), a phenomenon also recently found in studies with osteosarcoma cell lines [37]. Cells with cytoplasmic CD133 were also positive for Tie2, whereby $\mathrm{Tie}^{+} /$ $\mathrm{CD}_{133^{+}}$double positive cells have lower levels of $\mathrm{CD} 133^{+}$than CD $133^{+} /$Tie $^{-}$cells (Figure S7). In summary, established ovarian cancer cell lines displayed a hierarchical organization similar to that found in primary cultures and their derived xenografts.

\section{Maintenance of stem or progenitor phenotypes in vitro and differentiation is dependent on substrate}

E/M-MP cells are enriched for tumor-forming cells and express both epithelial and mesenchymal markers (cytoplasmic Ecadherin, CD44) as well as high levels of the putative cancer stem cell marker CD133. These are all features that have been associated with cancer stem cells in the past. Other critical characteristics of stem cells in general are i) their multipotency. i.e ability to differentiate into different lineages under certain conditions, and ii) their ability to self-renew, i.e. maintain a subset of undifferentiated cells during differentiation.

i) EMT in vitro and maintenance of E/M-MP and E/M-E cells. Our finding that, during passaging, $\mathrm{E} / \mathrm{M}$ cells give rise to cultures that predominantly contain mesenchymal cells and lost surface CD133 indicates differentiation (Figure 3). Notably, during this process, a small subset of $\mathrm{CD} 133^{+}$cells is maintained and this subset expresses low to high levels of surface E-cadherin and high levels of CD44. The maintenance of potential cancer stem cells also explains the development of tumors after transplantation of passage 18 cells (see Figure 3D). Interestingly, when passage 18 cultures were subjected to stress in the form of serum/growth factor starvation, E/M-cells regain features of stem cells, particularly the expression of nuclear Nanog, indicating a potential reversion of E/ M-E to E/M-MP cells (Figure S8). To gather further evidence for differentiation of $\mathrm{E} / \mathrm{M}$ subsets, we analyzed early passage ovc316- 
A
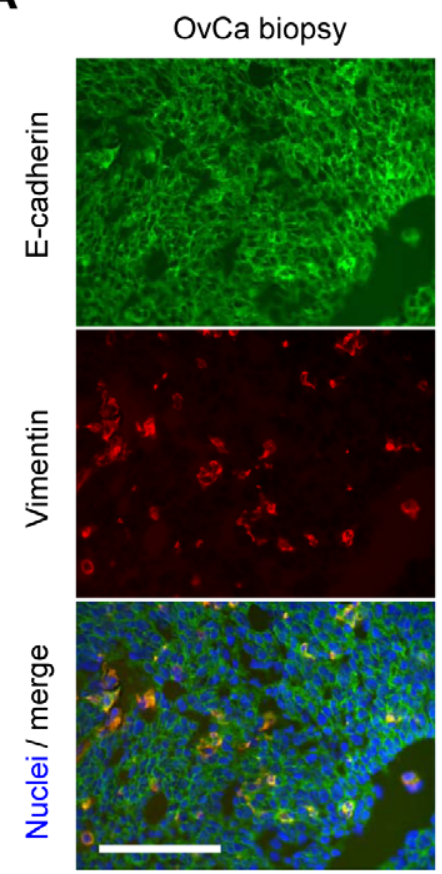

B
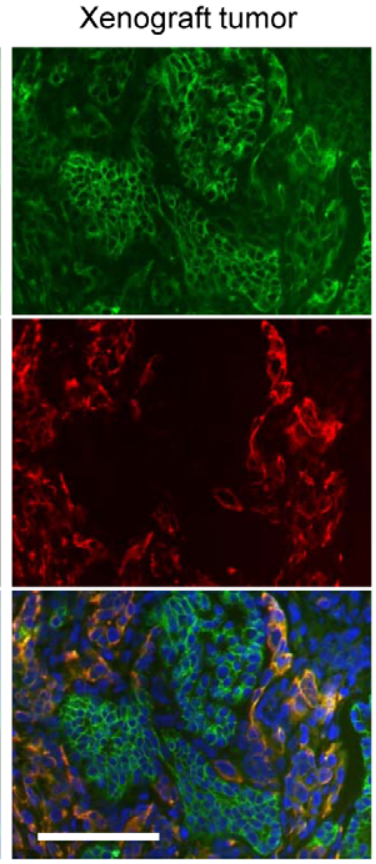
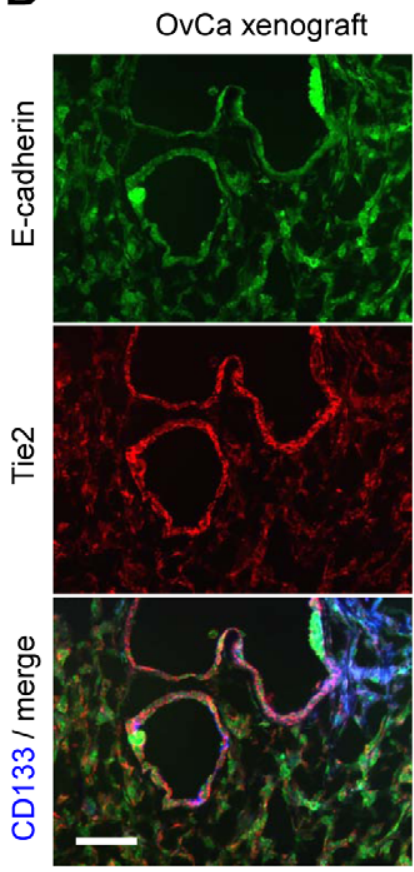

C

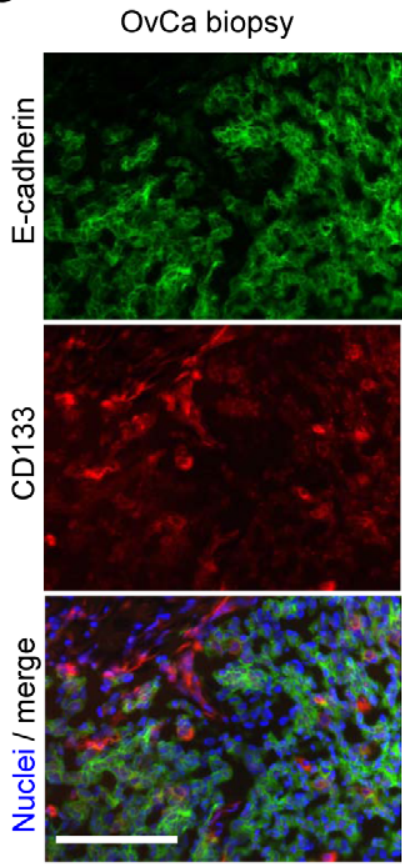

D
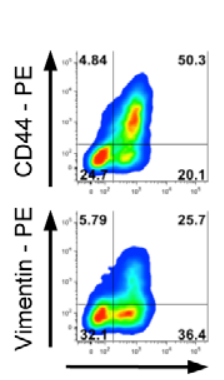

E
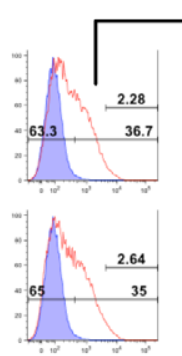

CD133 - APC

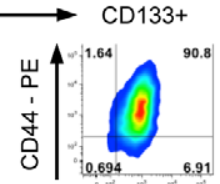

CD133+ high
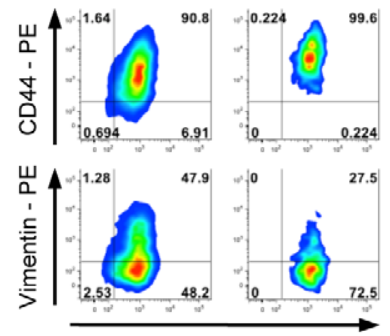

EpCAM - FITC
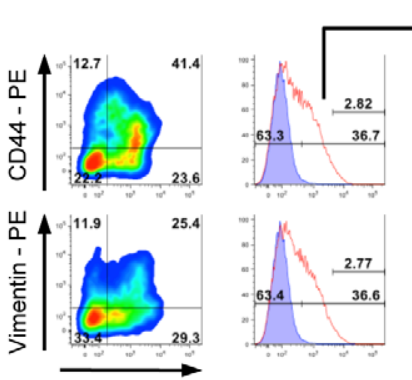

E-cadherin - AF488

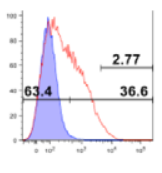

CD133 - APC
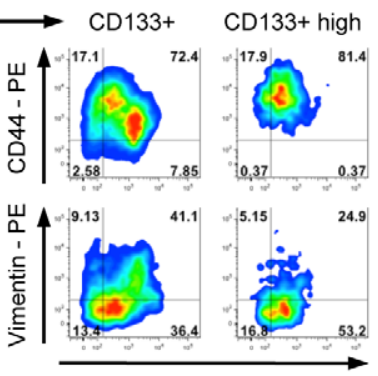

E-cadherin - AF488
F
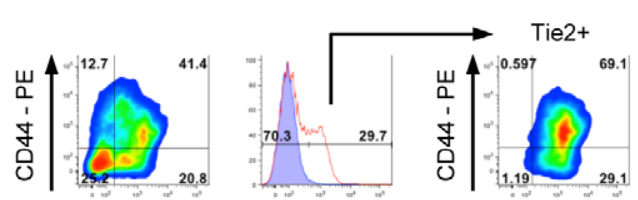

Tie2-
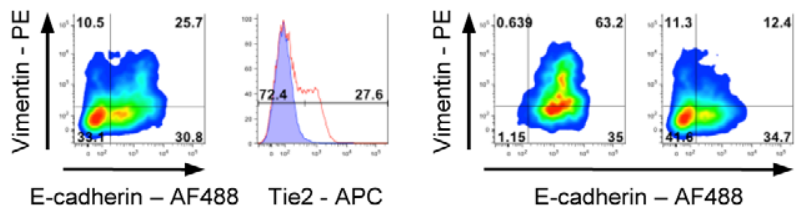

E-cadherin - AF488

Figure 4. Phenotypic analysis of ovarian cancer xenografts and biopsies. A) Existence of E/M hybrid cells in situ. E-cadherin ${ }^{+} /$vimentin $^{+}$cells are present biopsies and tumor xenografts. Shown are images of ovc316-biopsy and ovc316-X. Similar staining was found for ovc100506-biopsy/ ovc100506-X, ovc100728-biopsy/ovc100728-X, and ovc100914-biopsy/ovc100914-X. B) Correlation of E-cadherin (green) and Tie2 (red) positivity in ovarian cancer biopsies. CD133 ${ }^{\text {high }}$ cells (blue) are Tie2 $2^{\text {low }}$ and E-cadherin ${ }^{\text {intermediate }}$. Shown are images of ovc316-biopsy and ovc316-X. Similar staining was found for ovc100506-biopsy/ovc100506-X, ovc100728-biopsy/ovc100728-X, and ovc100914-biopsy/ovc100914-X. C) CD133 high cells have low levels of membrane E-cadherin. E-cadherin high cells show punctated membrane CD133 staining. Shown are images of ovc316-biopsy and ovc316-X. Similar staining was found for ovc100506-biopsy/ovc100506-X, ovc100728-biopsy/ovc100728-X, and ovc100914-biopsy/ovc100914-X. The scale bar is $40 \mu \mathrm{m}$. D-F) Triple-color flow cytometry analysis of ovc316-X for epithelial markers ( $x$-axis), mesenchymal features ( $y$-axis), and for cancer stem cell marker CD133 (histogram plots). D) Xenografts contain epithelial cells, epithelial/mesenchymal (E/M) hybrid cells, and cells that are negative for all markers. $\mathrm{CD}_{133^{+}}$cells are almost exclusively in an E/M hybrid stage based on EpCAM/CD44 analysis. CD133 ${ }^{\text {high }}$ cells are EpCAM ${ }^{\text {high }}, \mathrm{CD}^{\text {high }}$ and vimentin ${ }^{\text {low }}$. E) Replacement of EpCAM with E-cadherin reveals higher diversity within xenografts. CD44 ${ }^{\text {high }}$ cells are E-cadherin ${ }^{\text {low/intermediate }}$ CD $133^{+}$cells are divided into two clear sub-fractions. Fraction 1: E-cadherin ${ }^{\text {low/intermediate }} / C D 44^{\text {high }}$ and fraction 2: E-cadherin ${ }^{\text {high }} / \mathrm{CD} 4^{\text {intermediate }}$. $\mathrm{CD} 133^{\text {high }}$ cells are E-cadherin ${ }^{\text {low/intermediate }}, \mathrm{CD} 44^{\text {high }}$ and vimentin ${ }^{\text {low }}$. The positivity of CD44 and vimentin correlates inversely. F) Tie2 marks cells that are E-cadherin ${ }^{\text {high }} / \mathrm{CD} 44^{\text {intermediate }}$ and predominantly positive for vimentin. Tie2 ${ }^{-}$cells are highly depleted for CD133 sub-fraction 2 and for Ecadherin $^{\text {cells }} /$ vimentin ${ }^{\text {high }}$ cells.

doi:10.1371/journal.pone.0016186.g004 
A

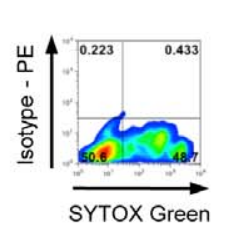

CD133+

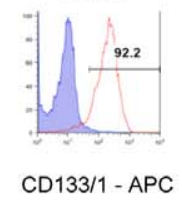

Tumor formation

\section{Injected cells}

10

100

1,000

$10^{4}$
CD133-

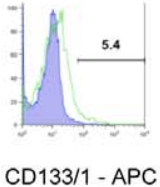

B

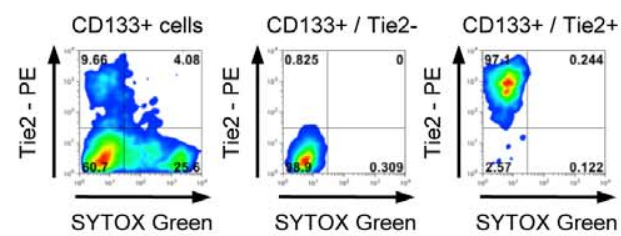

Tumor formation

$\begin{array}{llc}\text { Injected cells } & \text { CD133+/Tie2- } & \text { CD133+/Tie2+ } \\ 10 & 1 / 10 & 0 / 10 \\ 100 & 4 / 10 & 0 / 10 \\ 1,000 & 6 / 10 & 1 / 10\end{array}$

C

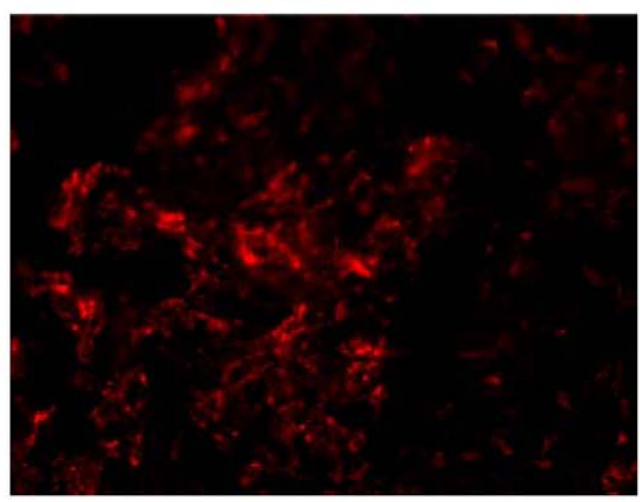

Tie2 E-cadherin

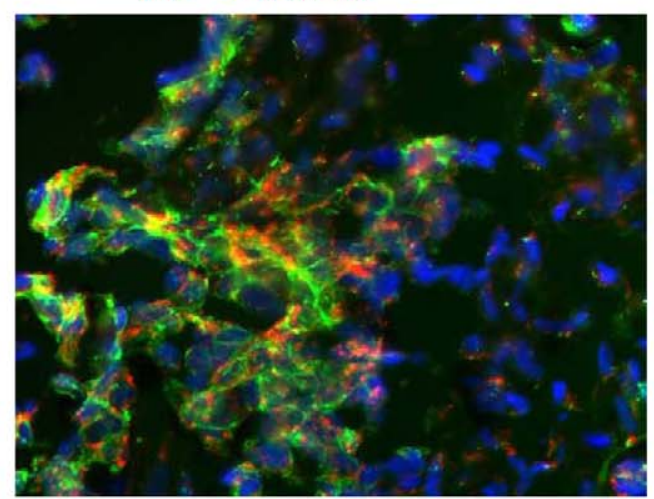

D

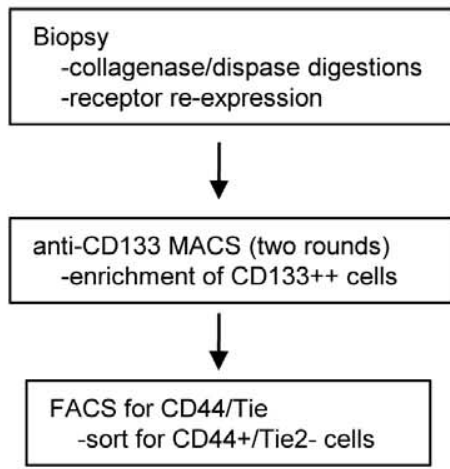

E

\section{Tumor formation}

\begin{tabular}{llc}
\hline Injected cells & CD133+/Tie2- & CD133+/Tie2+ \\
100 & $2 / 15$ & $0 / 15$ \\
1,000 & $8 / 15$ & $0 / 15$
\end{tabular}

Figure 5. Tumor forming ability of $\mathrm{CD} 133^{+}$subfractions. A) Validation of $\mathrm{CD} 133^{+}$cell fractions obtained by column isolation. Purity of injected cell fractions is shown. Cells used for transplantation were sorted by FACS and non-viable cells were excluded using SYTOX Green. Tumor-forming cells are highly enriched in the $\mathrm{CD} 133^{+}$cell fraction. Shown are studies with $\mathrm{CD} 133^{+}$vs $\mathrm{CD} 133^{-}$cells from eight pooled ovc316-X xenografts. $(\mathrm{N}=10$ animals per group). Tumor formation was evaluated 4 months after inoculation. TIC CD133 $: 1 / 191$, TIC CD133 $^{-}: 1 / 16725$. Chi-square $=8.25, p<0.01$. B) Column-isolated $\mathrm{CD} 133^{+}$cells were further subdivided into Tie $2^{+}$and Tie2 ${ }^{-}$fractions by FACS. Cells used for transplantation were sorted by FACS and non-viable cells were excluded using SYTOX Green. Tumor-forming abilities are more pronounced in CD133 ${ }^{+} /$Tie $2^{-}$cells. Shown are data from

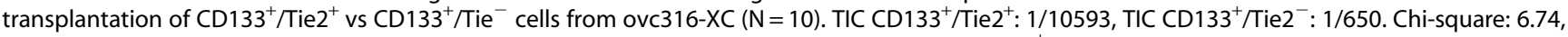

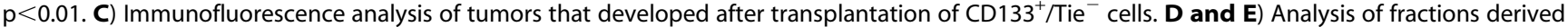
from patient biopsies. D) Schematic of cell isolation. E) Tumor formation after transplantation of $\mathrm{CD} 133^{+} / \mathrm{Tie}^{-}$and $\mathrm{CD} 133^{+} / \mathrm{Tie}^{+}$cells derived from ovc100506-biopsy. Tumor formation was evaluated 3 months after inoculation. TIC CD133 ${ }^{+} / \mathrm{Tie}^{-}: 1185, \mathrm{TIC} \mathrm{CD} 133^{+} / \mathrm{Tie}^{+}$: n.a. doi:10.1371/journal.pone.0016186.g005

CX cells for cell viability after detachment using versene (Figure 7A). In agreement with earlier experiments, we found high numbers of $\mathrm{CD} 133^{+}$and Tie $2^{+}$cells, whereby the majority of $\mathrm{CD}_{133^{+}}$and $\mathrm{Tie} 2^{+}$cells are mutually exclusive. $\mathrm{Tie} 2^{+} / \mathrm{CD} 133^{+}$ double positive cells have lower levels of $\mathrm{CD} 133^{+}$than $\mathrm{CD} 133^{+}$/ Tie $2^{-}$cells. The vast majority of Tie $2^{+}$cells stain positive for the dead cell marker 7AAD after treatment with versene, indicating their loss of resistance to anoikis after detachment, and therefore a 
A

B

SKOV3-ip1 (in vitro)
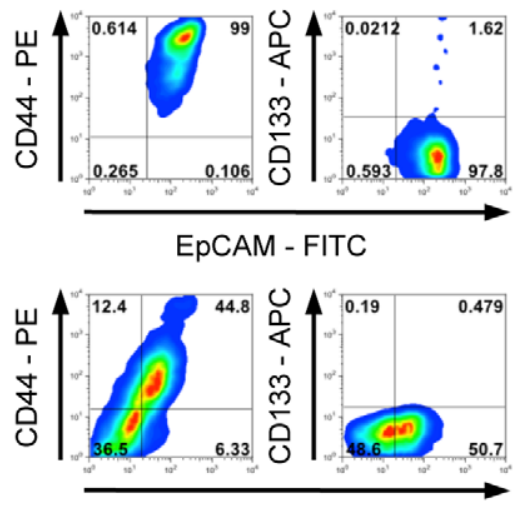

EpCAM - FITC

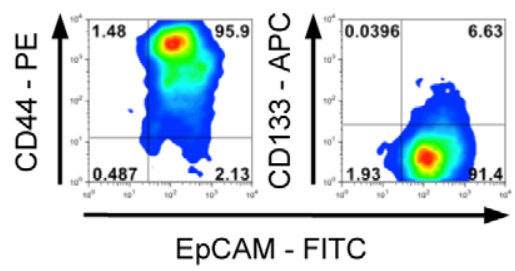

OVCAR5 (xenograft)

C
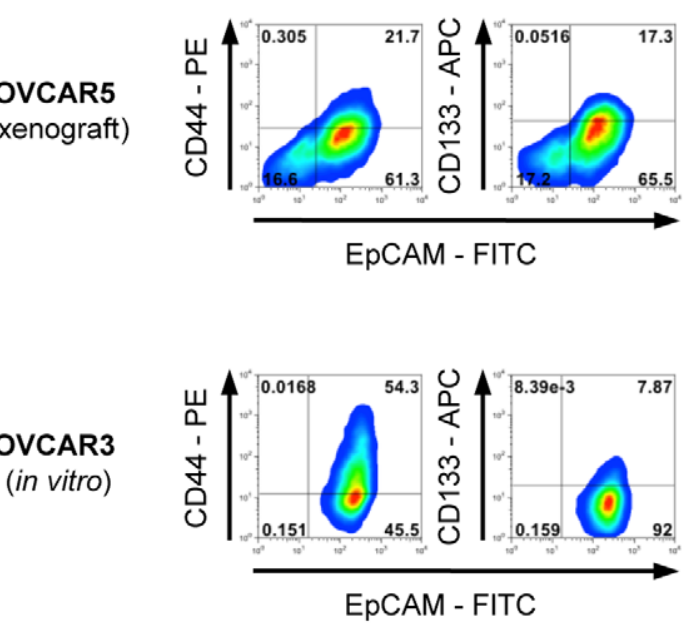

OVCAR3

(in vitro)

OVCAR5

(in vitro)

EpCAM - FITC

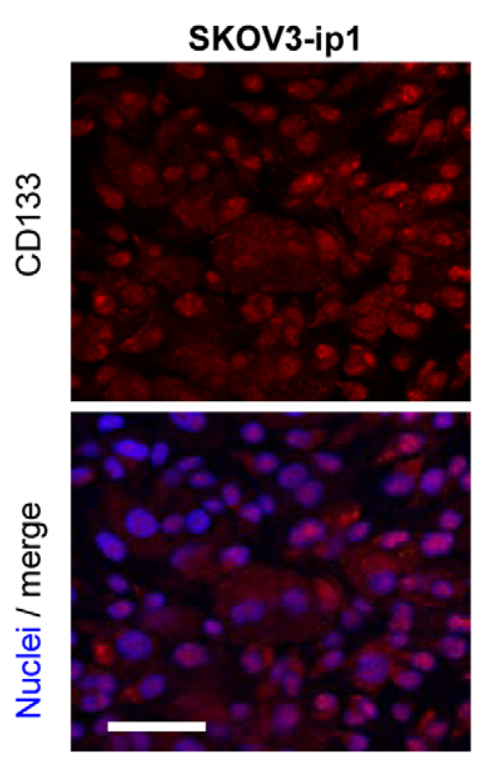

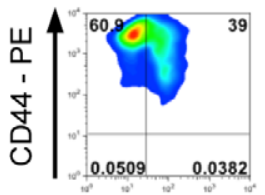

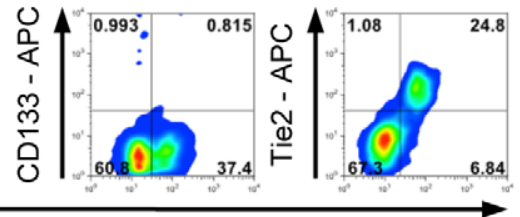

E-cadherin - AF488

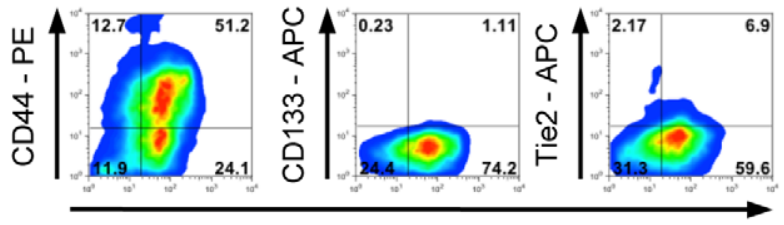

E-cadherin - AF488

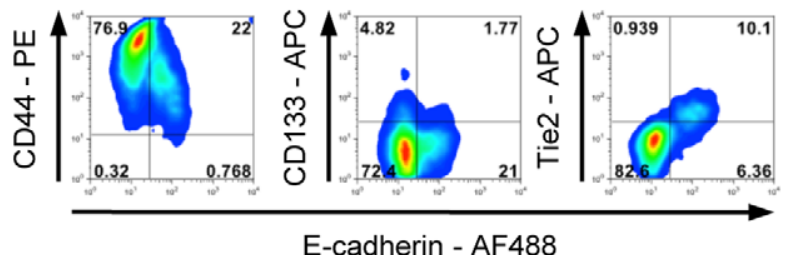

E-cadherin - AF488
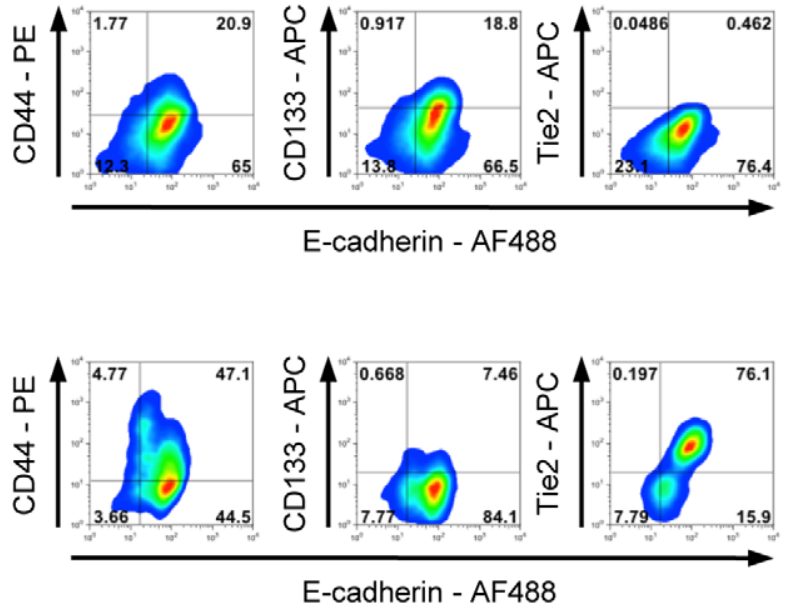

OVCAR5
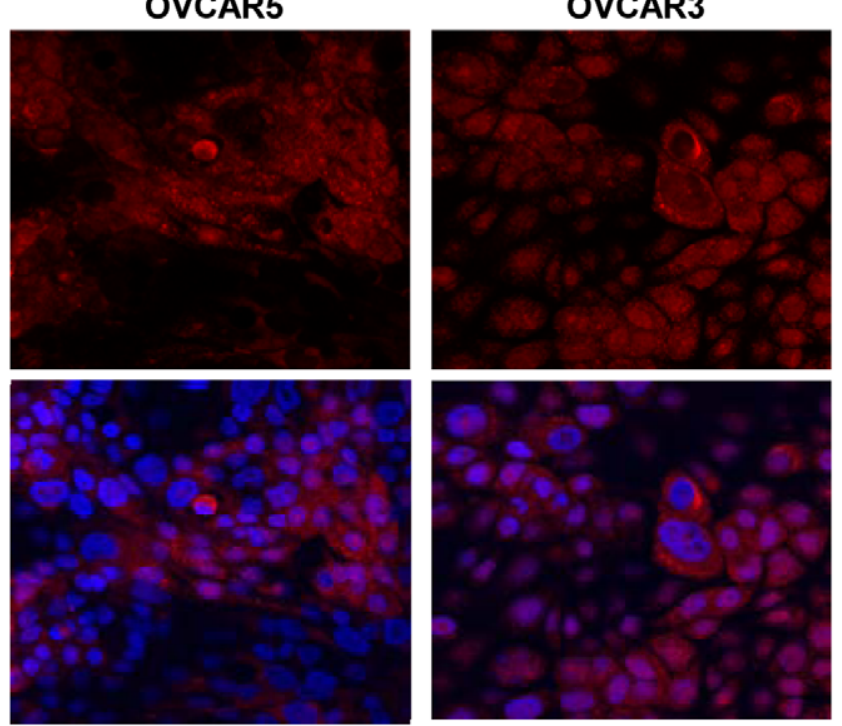
Figure 6. Characterization of cellular phenotypes within ovarian cancer cell lines in vivo and in vitro. A-C) Flow cytometry analysis for indicated markers in ovarian cancer cell lines. Upper panels show cellular phenotypes of cultures in vitro, lower panels show phenotypes of cells in vivo (xenografts). In vitro cultures of SKOV3-ip1 (A) and OVCAR-5 (B) contain high numbers of CD44 ${ }^{+}$cells and are enriched for E-cadherin negative cells. Tumor xenografts are highly epithelial. C) Non-tumorigenic OVCAR-3 cells have low CD44 levels and a highly epithelial phenotype in vitro. D) Immunofluorescence analysis of indicated ovarian cancer cell lines for CD133. Note that SKOV3-ip1 cells have low CD133 surface levels by flow cytometry, but contain high amounts of CD133 in the cytoplasm. The scale bar is $40 \mu \mathrm{m}$. doi:10.1371/journal.pone.0016186.g006

higher degree of differentiation. Viable cells show higher mean fluorescence of CD44 and CD133. All attached cells are positive for the cell proliferation marker Ki-67.

ii) MET in vivo. Another indication of differentiation comes from xenotransplantation studies. Cells used for transplantation were in passage 1 to 3 and the vast majority of cells were E/M cells. Importantly, the tumors that were derived from these cells were comprised of clusters of $\mathrm{E} / \mathrm{M}$ cells $\left(\mathrm{E}\right.$-cadherin ${ }^{+} /$vimentin $^{+}$ and $\mathrm{EpCAM}^{+} /$vimentin $^{+}$) as well as clusters of epithelial cells EpCAM $^{\text {high }}$ or Ecadherin $\left.{ }^{\text {high }}\right)$. The presence of epithelial cells in tumors, i.e. a cell type that was absent in the inoculated cells, indicate that $\mathrm{E} / \mathrm{M}$ cells differentiate towards epithelial cells in vivo, in a process reminiscent of MET. Maintenance and differentiation of cancer stem cells is also supported by the finding that transplantation of Tie $2^{-}$cells resulted in tumors consisting of Tie2-positive epithelial cancer cells and Tie $2^{-}$cells (representing less differentiated cells or cancer stem cells).

iii) Differentiation of E/M-MP cells depending on substrate (Figure 7B). To further support differentiation of $\mathrm{E} / \mathrm{M}$ cells in vitro, we isolated CD133 high cells from tumor xenografts and sorted them for viable CD $133^{\text {high }} /$ E-cadherin ${ }^{\text {low }}$ and CD133 ${ }^{\text {high }} /$ E-cadherin ${ }^{\text {high }}$ cells. When cultured at low cell densities, sorted CD133 $3^{\text {high }} / \mathrm{E}$-cadherin ${ }^{\text {high }}$ and CD133 $3^{\text {high }} / \mathrm{E}$ cadherin ${ }^{\text {low }}$ cells differentiate into similar cell populations with a mainly epithelial phenotype and low CD133 levels. We then cocultured the two different cell fractions with either epithelial or mesenchymal cells. For the latter we used epithelial (E) and mesenchymal (M) clonal cultures (see Figure 1G). Cell membrane dye PHK26 was used to discriminate substrate $\mathrm{E}$ or $\mathrm{M}$ cells (PHK26 positive) and cells derived from the sorted CD133 ${ }^{+}$ populations (PHK26 negative). When co-cultured with $\mathrm{E}$ or $\mathrm{M}$ cells at a ratio of $1: 10, \mathrm{CD} 133^{\text {high }}$ cells differentiate into epithelial or mesenchymal cells, depending on the provided environment. Notably, sorted CD133+/E-cadherin high generated more Ecadherin-positive cells than sorted $\mathrm{CD} 133^{+} /$E-cadherin ${ }^{\text {low }}$ cells when cultured among $\mathrm{M}$ cells (Figure 7B).

A gain in epithelial features, particularly in E-cadherin is thought to occur early in ovarian cancer development. We therefore studied the phenotype of non transformed ovarian surface epithelial cells.

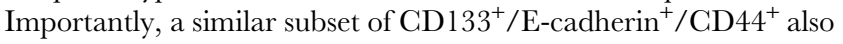
exists in early passage ovarian surface epithelial (OSE) cells (Figures $7 \mathrm{C}$ and D). This subset comprises less than $1 \%$ of the total culture. In striking difference to ovc316-XC cells, E-cadherin levels for the vast majority of OSE cells are low. Tie $2^{+}$cells in OSE and ovarian cancer cultures are enriched for E-cadherin and show lower mean fluorescence for CD44 than CD $133^{+}$cells.

\section{Activation of EMT pathways during passaging of ovc316- $X C$ cells}

The finding that E/M cells undergo EMT in vitro is supported by the analysis of signaling pathways using Western blot with antibodies to key kinases (Figures 8A). It is generally accepted that EMT is characterized by the activation of several kinases, including ERK1, ERK2, and PI3K/AKT [17]. Xenograft tumors contain high amounts of E-cadherin and CD133, which decrease after culturing. Concomitant with a loss of these markers is a switch from phophorylated p38 to phophorylated ERK44/42.
Adaption to tissue culture (compare ovc316-X tumor and ov316$\mathrm{XC}$ pl) is also associated with ERK44/42 and cRAF1 activation. The decrease in the phosphorylated form of the stress kinase p38 can most likely be explained by the loss of ECM and integrin signaling when cells are removed from tumor xenografts.

The activation of pathways during in vitro passaging is further corroborated by studies using specific phosphokinase inhibitors (Figures 8B-D). The inhibition of Raf, MKK, or JNK significantly decreases proliferation rates of ovc316-XC cells. The inhibition of p38 increases the number of viable cells. Flow cytometry shows the presence of the two E/M-MP and E/M-E (E-cadherin high/ CD $44^{\text {high }}$ or E-cadherin ${ }^{\text {low }} / \mathrm{CD} 44^{\text {high }}$ ) fractions (Figure 8D). Inhibition of JNK, Raf, and growth factor starvation decreases the mean level of CD44. Growth factor starved and JNK-inhibited cells are highly epithelial and CD133 positive indicating that JNK pathways are also involved in mediating EMT. In the presence of JNK inhibitor, cells differentiate into epithelial cells/progenitors $\left(\mathrm{CD} 44^{\text {low }}, \mathrm{CD} 133^{\text {intermediate }}\right)$ instead. The inhibition of Raf and MKK/ERK highly depletes ovc316-XC cultures for E-cadherin $^{\text {high }} / \mathrm{CD} 44^{\text {high }}$ cells, indicating that Raf and ERK are important for proliferation and maintenance of undifferentiated epithelial cells (E-cadherin $\left.{ }^{\text {high }} / \mathrm{CD} 44^{\text {high }}\right)$. The inhibition of p38 increases the mean level of CD44, demonstrating a role for p38 in the maintenance of undifferentiated epithelial cells (E-cadherin ${ }^{\text {high }}$ / CD44 $\left.{ }^{\text {high }}\right)$. Taken together, pathway and inhibitor analyses support the presence of EMT in vitro upon culturing of ovarian cancer cells.

\section{Discussion}

For this study we investigated the characteristics of human ovarian cancer cells derived from patient tumor biopsies. Our conclusions are based on the analysis of 14 different biopsies, 10 primary ovarian cancer cultures, 4 xenografts and cultures thereof. In the different cellular subsets found within these tumors we noticed a number of phenotypic features, which are summarized in Figure 9A. Our best understanding of the interconnections between these diverse subsets in relation to their relative mesenchymal or epithelial status is described in Figure 9B. In primary ovarian cancer cultures and tumors in situ we found cells that were in an epithelial and mesenchymal $(\mathrm{E} / \mathrm{M})$ hybrid stage. Based on the differences in the levels of the markers E-cadherin, CD133, Tie2 and CD44, we defined different subsets within E/M cells that differed in pluripotency and tumorigenicity. A multipotent, tumorigenic $\mathrm{E} / \mathrm{M}$ cell subset (E/M-MP), that fits the profile of true cancer stem cells, had high levels of cytoplasmic E-cadherin, membrane CD133 and membrane CD44. This subset also expressed markers of other lineages, including CD31, VCAM-1 and caldesmon, and displayed features of stem cells, including the presence of nuclear-localized Nanog. MACS and FACS based separation of this subset was possible based on the presence of CD133 and CD44, and the absence of Tie2. Several lines of data indicate that these E/M-MP cells are multipotent. We found that transplantation of CD $133^{\text {high }} /$ membrane E-cadherin low/intermediate $/$ cytoplasmic E-cadherin $^{+} / \mathrm{Tie}^{-}$resulted in tumors consisting of membrane E-cadherin ${ }^{\text {high }}$ /Tie2-positive cells, indicating that tumor growth in vivo is driven by E/M-MP cells, which give rise to an $\mathrm{E} / \mathrm{M}$ subset, with more dominant epithelial 
A

Attached cells

Viable cells

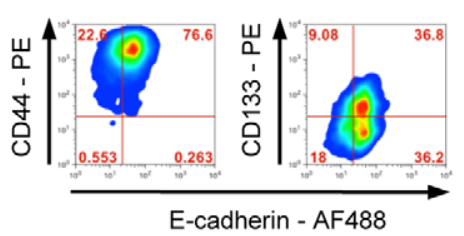

E-cadherin - AF488

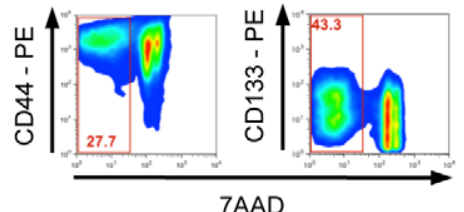

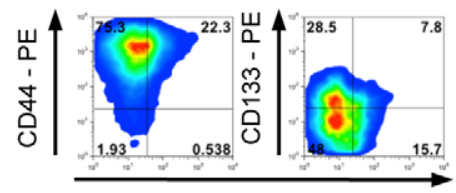

Tie2 - APC
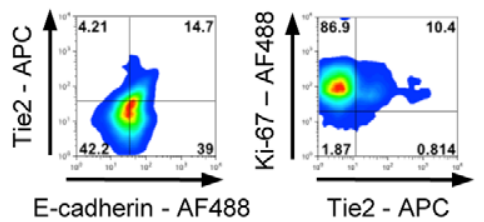

B

Monoculture
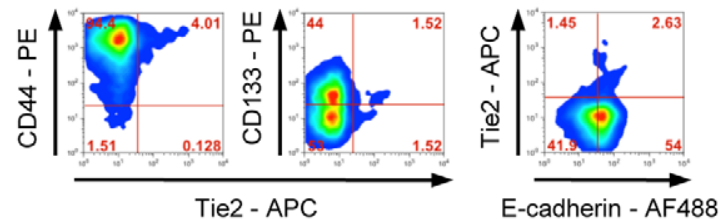

\section{Monocher \\ Co-culture with} epithelial cells

Co-culture with mesenchymal cells

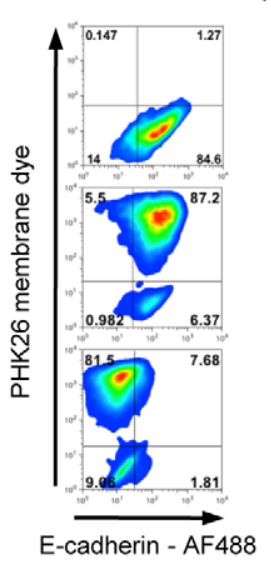

Gating for
PHK26negative cells
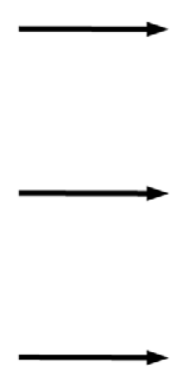

$\mathrm{CD} 133+$ I CD133 + I

$\mathrm{E}$-cadherin low $\mathrm{E}$-cadherin high

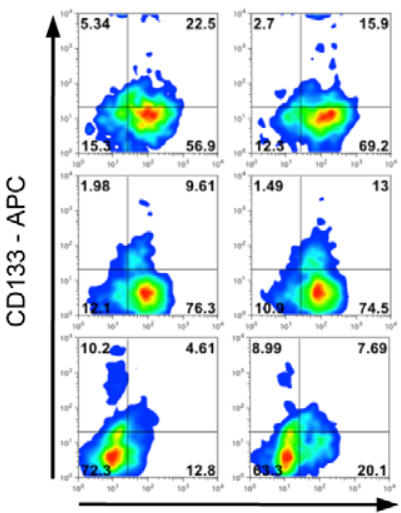

E-cadherin - AF488
C

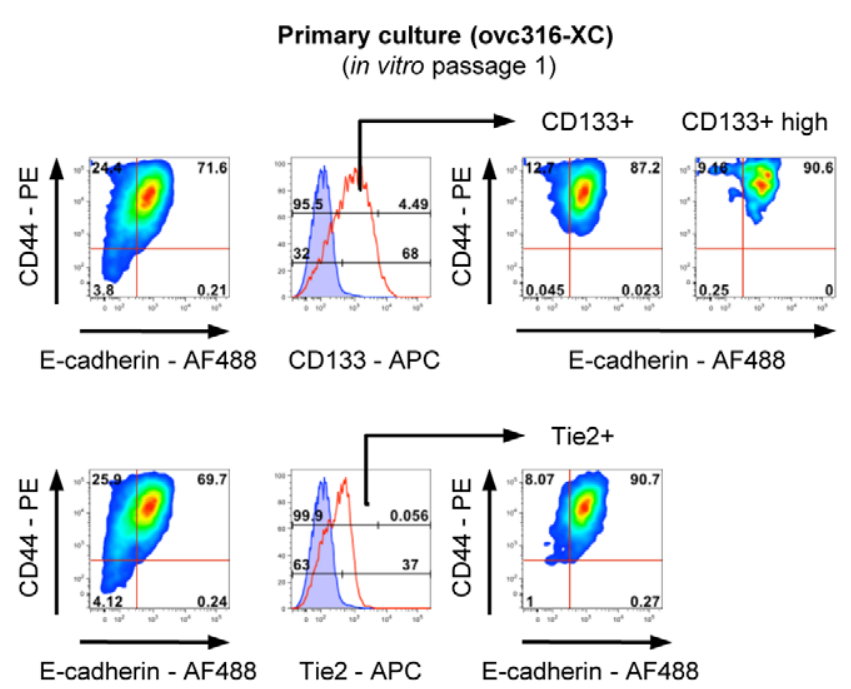

D
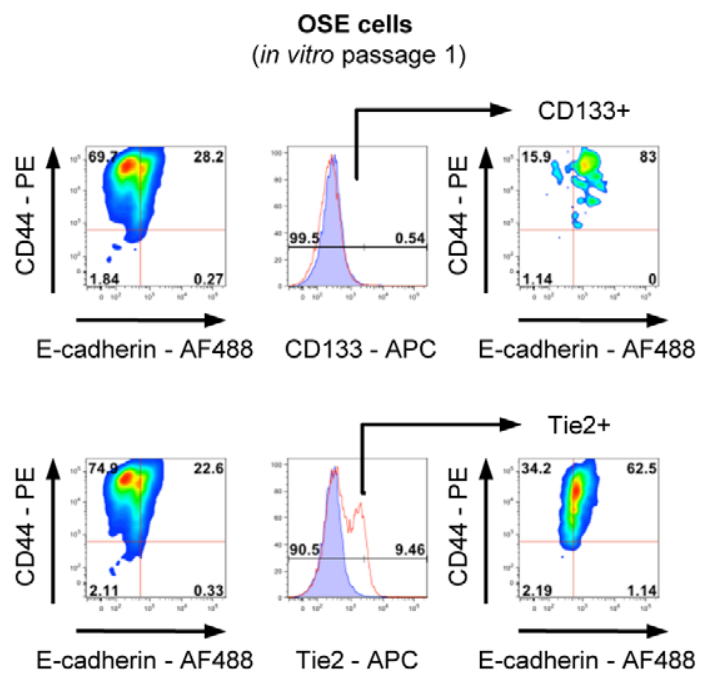

Tie2+

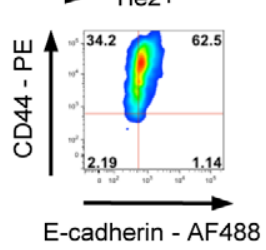

Figure 7. Differentiation potential of $\mathrm{CD} 133^{+}$cells. A) Viability of different subsets. Low passage ovc $316-\mathrm{XC}$ cells contain high numbers of $\mathrm{CD} 133^{+}$and Tie2 $2^{+}$cells. Tie $2^{+} / \mathrm{CD} 133^{+}$double positive cells have lower levels of $\mathrm{CD} 133^{+}$than $\mathrm{CD} 133^{+} / \mathrm{Tie2}^{-}$cells. The vast majority of Tie2 ${ }^{+}$cells stains positive for the dead cell marker 7-AAD after treatment with versen. Viable cells show higher mean fluorescence of CD44 and CD133. All attached 
cells are positive for the cell proliferation marker Ki-67. B) CD133 ${ }^{+}$cells isolated from ovc316-XC tumor xenografts adapt to their environment. When cultured at low cell densities, sorted $\mathrm{CD} 133^{+} / \mathrm{E}$-cadherin ${ }^{\text {high }}$ and $\mathrm{CD} 133^{+} / \mathrm{E}$-cadherin ${ }^{\text {low }}$ cells differentiate into similar cell populations with an epithelial phenotype. When co-cultured with clonal ovc316-XC epithelial or mesenchymal cultures (ratio 1:10), CD133 ${ }^{+}$cells differentiate into epithelial or mesenchymal cells, depending on the environment. Cell membrane dye PHK26 was used to discriminate between clonal cells (PHK26 positive) and cells derived from the CD133 $3^{+}$population (PHK26 negative). Cells were cultured for 7 days. C and D). Similarities between primary ovarian cancer cells and normal ovarian surface epithelial cells (OSE). Early passage OSE cells show high similarities with early passage ovarian cancer cultures. OSE cultures are low in E-cadherin and are $\mathrm{CD} 133^{+}$. CD133 $3^{+}$cells within OSE and ovarian cancer cultures are enriched in cells positive for E-cadherin and CD44. Tie2 $2^{+}$cells in OSE and ovarian cancer cultures are enriched for E-cadherin and show lower mean fluorescence for CD44 than CD133 ${ }^{+}$cells. doi:10.1371/journal.pone.0016186.g007

features (E/M-E), and subsequently to epithelial cells that lacked all mesenchymal and stem cell traits, and that had lost the ability to form tumors (when isolated in vitro in the form of clonal cultures)
(Figure 9B, left scheme). Therefore, tumor growth in xenografts appears to involve processes reminiscent of MET. Corresponding MET-inducing signals might emanate from the tumor-associated
A

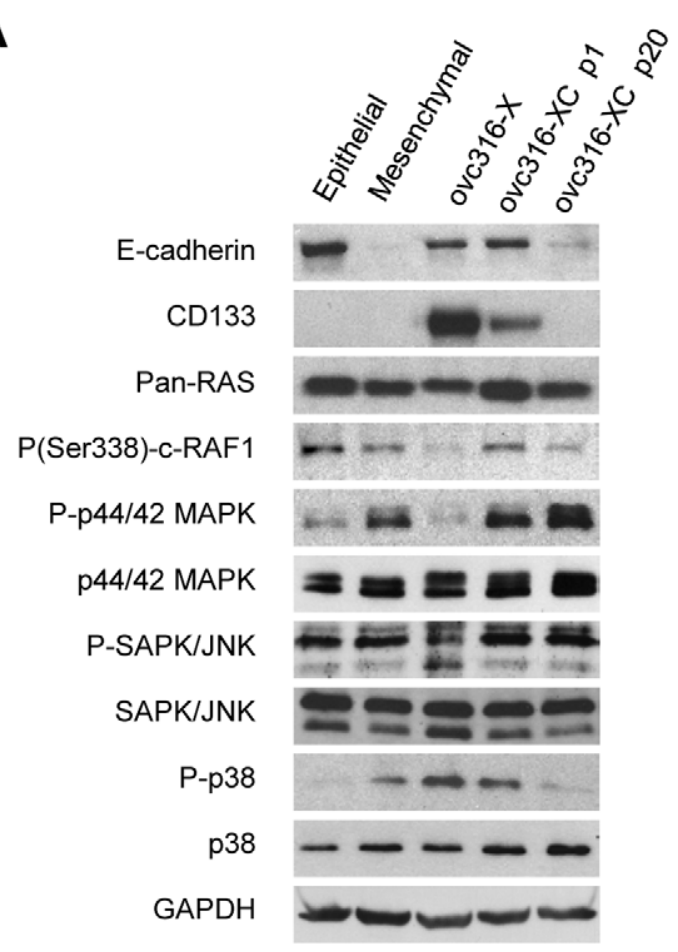

B

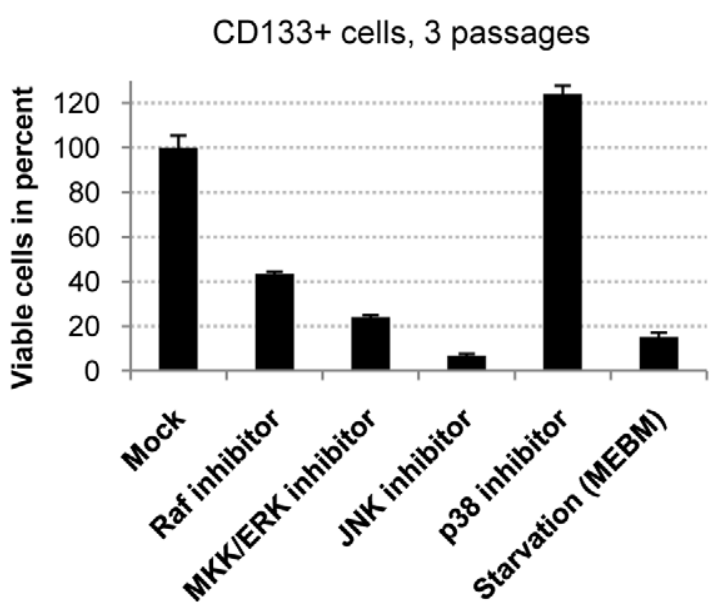

C
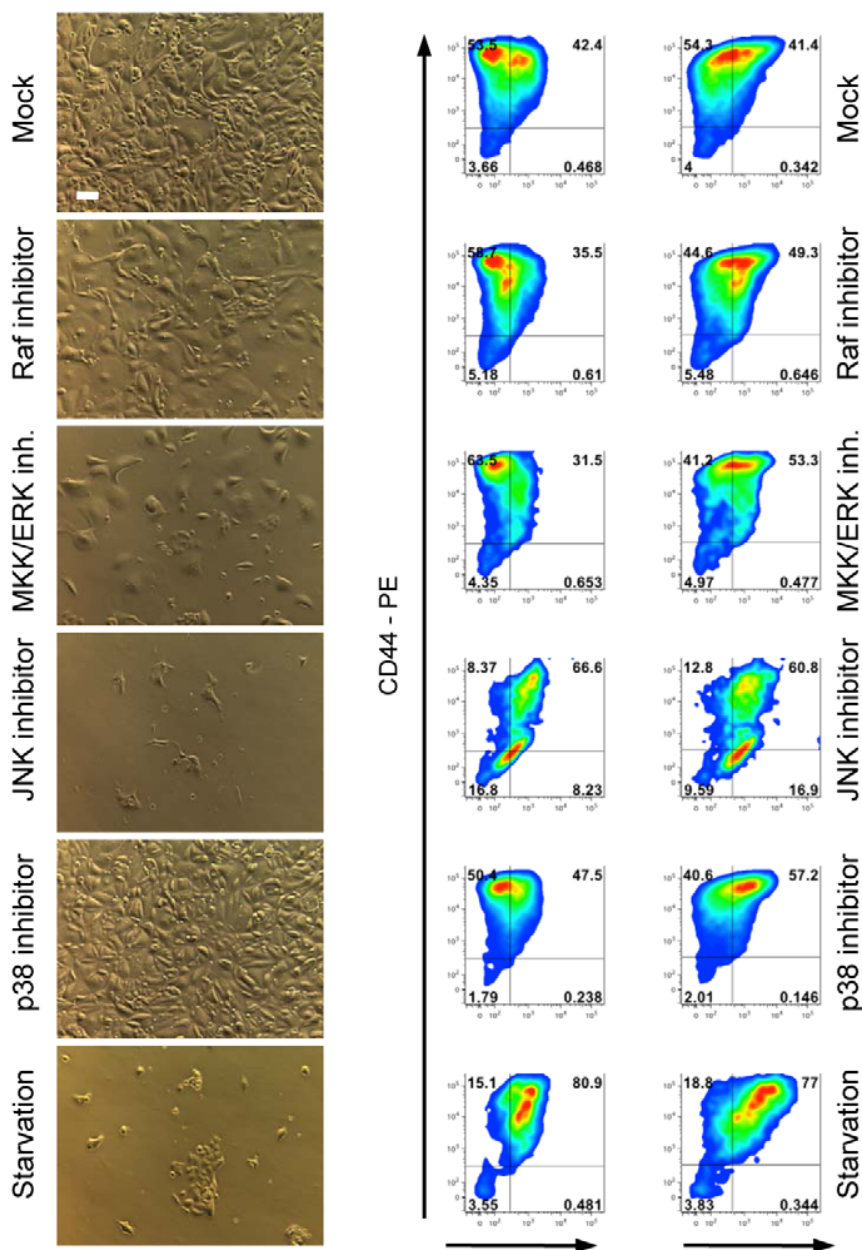

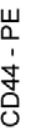
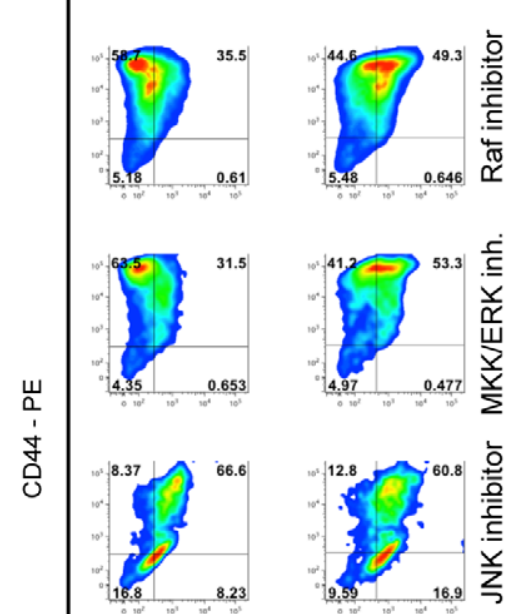

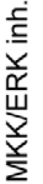

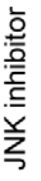
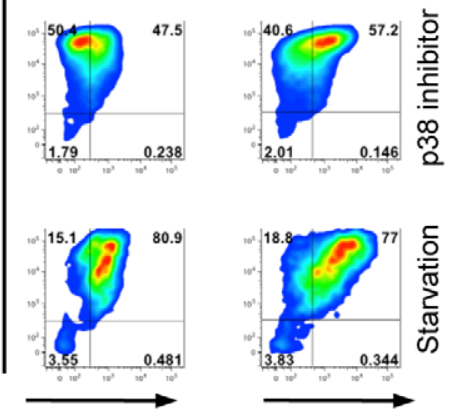

E-cadherin - AF488

Figure 8. Impact of MAP kinases on proliferation and differentiation in CD133 ${ }^{+}$derived cells. A) Western blot analysis of E-cadherin, CD133 and the MAPK pathway in ovc316-XC tumor xenografts, low passage (p1), high passage (p20), and in clonal epithelial and mesenchymal cultures. Xenograft tumors contain high amounts of E-cadherin and CD133, which decrease after culturing. Concomitantly with a loss of these markers occurs a switch from phophorylated p38 to phophorylated ERK44/42. B) Impact of MAPK pathway inhibitors on proliferation. Cells (p7) were passaged in the presence of inhibitors for 21 days. C) Bright field analysis of ovc316-XC cells cultured in the presence of indicated inhibitors after 21 days. The scale bar is $40 \mu \mathrm{m}$. D) Flow cytometry analysis of ovc316-XC cells cultured in the presence of indicated inhibitors after 21 days $(\mathrm{N}=3)$. doi:10.1371/journal.pone.0016186.g008 
stroma, be due to the relative lack of growth factors (compared to in vitro cultures), and/or be caused by the 3-dimensional organization of tumor cells.

In contrast, we found in vitro indication of E/M-MP cells differentiating into mesenchymal cells, through the process of EMT (Figure 9B, right scheme). Of all the cells in suspensions derived from patient biopsies or xenografts, only E/M hybrid cells (E/M-MP and rare E/M-E) adapted to tissue culture and were found in early cell passages. After passaging these E/M cells differentiated into mesenchymal cells that lacked epithelial or stem cell markers and tumor forming ability. Our findings are suggestive for EMT, however could theoretically also be due to selective expansion of specific cell subsets. The following data support EMT rather than selective expansion: i) E/M cells express EMT inducers such Snail, Twist and NGAL (Figure 2D), ii) in vitro culturing is associated with the activation of EMT pathways (ERK1, ERK2, and PI3K/AKT) during culturing and passaging (Figure 8), iii) Studies with clonal cultures showed that epithelial cells can lose membrane E-cadherin and claudin 7 and acquire the mesenchymal transcription variant of p120 catenin (Figure S1), and iv) the same $\mathrm{CD} 133^{+} \mathrm{E} / \mathrm{M}$ cells give rise to either epithelial or mesenchymal cells when cultured on epithelial or mesenchymal substrates, respectively (Figure 7B). We speculate that activation of EMT programs in vitro is facilitated by the disruption of cell-cell

\section{A}

\begin{tabular}{|c|c|c|c|c|c|c|c|c|c|c|c|c|c|}
\hline $\begin{array}{l}\text { Ovarian } \\
\text { cancer cell } \\
\text { subset }\end{array}$ & in vivo & in vitro & $\begin{array}{l}\text { Tumor } \\
\text { formation }\end{array}$ & $\begin{array}{l}\text { Anoikis } \\
\text { resistant }\end{array}$ & $\begin{array}{l}\text { Membrane } \\
\text { E-cadherin }\end{array}$ & $\begin{array}{l}\text { Intracellular } \\
\text { E-cadherin }\end{array}$ & EpCAM & Tie2 & Vim & CD44 & CD133 & $\begin{array}{l}\text { Stem } \\
\text { cell } \\
\text { markers }\end{array}$ & $\begin{array}{l}\text { Other } \\
\text { lineage } \\
\text { markers }\end{array}$ \\
\hline $\begin{array}{l}\text { E/M-MP } \\
\text { multipotent }\end{array}$ & + & + & ++ & + & $+1-$ & + & + & - & $+1-$ & ++ & ++ & + & + \\
\hline $\begin{array}{l}\text { E/M-E } \\
\text { epithelial traits } \\
\text { (reversible) }\end{array}$ & + & + & $+1-$ & + & ++ & - & + & + & + & + & + & $+1-$ & $+1-$ \\
\hline $\begin{array}{l}\text { E-progenitors } \\
\text { committed } \\
\text { (irreversible) }\end{array}$ & + & + & - & - & ++ & - & + & + & + & $+1-$ & $+1-$ & $+1-$ & $+1-$ \\
\hline $\begin{array}{l}\text { E } \\
\text { epithelial, } \\
\text { terminally } \\
\text { differentiated }\end{array}$ & + & - & - & - & + & $+1-$ & + & - & - & - & - & - & - \\
\hline $\begin{array}{l}\text { M } \\
\text { mesenchymal, } \\
\text { terminally } \\
\text { differentiated }\end{array}$ & - & + & - & + & - & $+1-$ & - & - & + & + & - & $+1-$ & $+1-$ \\
\hline
\end{tabular}

B

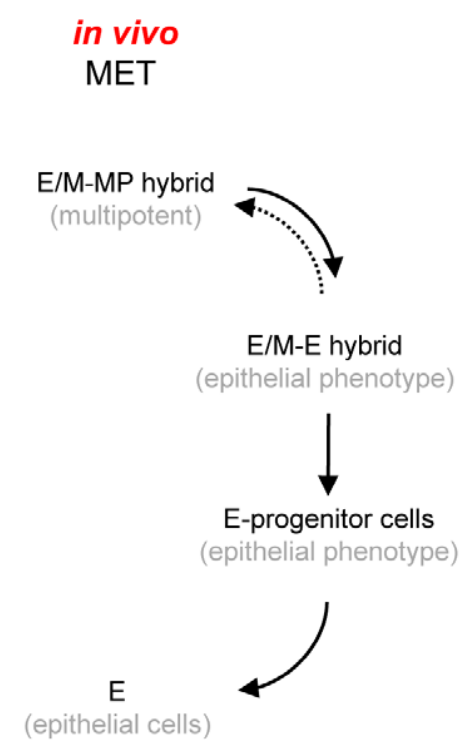

\section{in vitro \\ EMT}

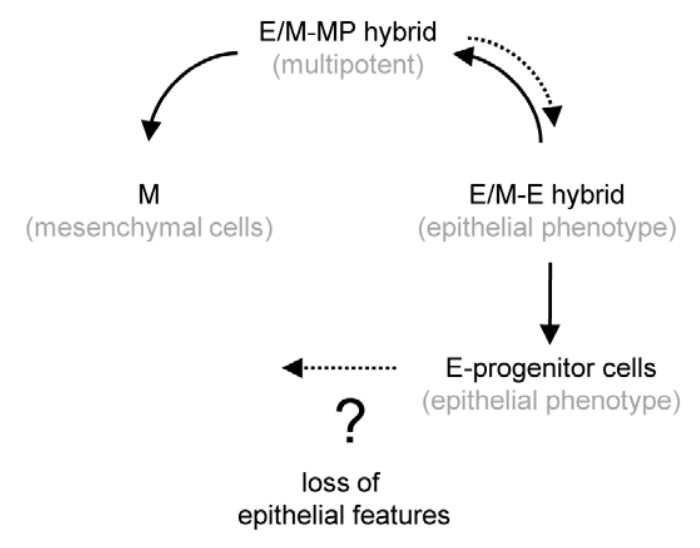

Figure 9. Cellular subsets in human ovarian cancer. A) Summary of phenotypic markers found in different ovarian cancer subsets. B Interconnection between different subsets. (Description in text).

doi:10.1371/journal.pone.0016186.g009 
adherens junctions, due to culture medium supplements such as EGF, and the cell-ECM adhesions mediated by integrins.

Interestingly, E/M cells isolated from xenografts seem to be initially primed towards epithelial differentiation for a number of passages, as supported by several experiments (Figure 3, Figure S3A). Here, the maintenance of high CD133 levels and selfrenewal of undifferentiated cells depends on high cell densities (Figure 3, Figure S3A). The accelerated cell division of undifferentiated E/M cells might be supported by the high production of extracellular matrix proteins, observed in early passages (Figure 3C), whereas low cell densities of E/M-MP cells, or growth among more differentiated cells, enforces differentiation and the rapid loss of CD133 (Figures 7A,B). Moreover, the phenotypic plasticity of E/M-MP cells and their daughter cells highly depends on the provided cellular environment. During in vitro passaging, EMT-inducing events trigger the generation of Ecadherin $^{\text {negative }}$ cells, which is accompanied by the loss of CD133 and lowered secretion of ECM components (Figure 3). The culturing of E/M-MP cells among mesenchymal cells accelerates the loss of E-cadherin, whose maintenance on the cell surface requires homophilic intercellular connection.

Our data also indicates that the composition of $\mathrm{E} / \mathrm{M}$ subsets fluctuates when cultures are exposed to stress such as starvation. Cultures that were subjected to starvation become enriched for cells with stem cell features (e.g. presence of Nanog in nuclei, shift from membrane E-cadherin to nuclear E-cadherin). This indicates that E/M-E cells can revert to E/M-MP cells and vice versa in vitro and potentially in vivo (dashed arrows, Figure 9B). Furthermore, our in vitro data suggests the existence of committed epithelial progenitor cells (membrane E-cadherin ${ }^{\text {high }}$, CD $133^{\text {intermediate/low }}$, CD $\left.44^{\text {intermediate }}, \mathrm{Tie}^{+}\right)$that lost resistance to anoikis and the ability to revert into E/M-E and E/M-MP cells. We also speculate that these cells might be able to lose E-cadherin and convert, through a secondary EMT, into more differentiated mesenchymal cells (Figure 9B, dotted arrow). A similar process is thought to occur late in ovarian cancer development and during ovarian cancer metastasis. As discussed earlier, subfractions and processes similar to those described by us for primary ovarian cancer cells appear to exist in the development of ovarian cancer.

A central conclusion from our studies of ovarian cancer is the existence of E/M hybrid cells. Our data suggest that specific E/M subsets are pluripotent, i.e. have the ability to transdifferentiate into epithelial and mesenchymal cancer cells through MET and EMT, respectively. EMT in the context of the CSC concept in breast cancer was recently reported by Weinberg's group. They found that induction of EMT through over-expression of Snail or Twist in human mammary epithelial cells caused these cells to exhibit cell surface markers similar to those of cancer stem cells, such as CD $44^{\text {high }} /$ CD24 $4^{\text {low }}$ [38]. These and other studies on prostate cancer [39] indicate that EMT-like events, i.e. the generation of mesenchymal-like cells, are associated with an increase in tumor-forming capacity. In contrast, we found in our studies with ovarian cancer cells that cultures, which predominantly contain mesenchymal cells are less tumorigenic than E/M cultures from which they are derived from. We speculate that this discrepancy is due to intrinsic differences between ovarian cancer and other epithelial cancers [25].

We also found that E/M-MP cells have endothelial traits (CD31, VCAM-1). Notably, two recent publications have shown that glioma stem cells can differentiate into endothelial cells and generate tumor vasculature $[40,41]$.

Furthermore, our data suggest that ovarian cancer displays both a spatial and temporal heterogeneity involving tumor cell subsets that differ in their ability to form tumors and differentiate. Ovarian cancers are composed of tumor-driving E/M-MP cells as well as non-tumorigenic differentiated cancer cells that compose the bulk of cells in a tumor. This observation has implications for tumor therapy, which is often directed toward markers found on epithelial cancer cells (e.g. Her2/neu, EGFR, FGFR).

Future studies will have to focus on the delineation of the genetic and epigenetic differences between cellular subsets. These studies will also clarify the currently widely discussed question about whether tumor heterogeneity is due to distinct clones from different CSCs or whether CSCs, like their normal counterparts, are multipotential. A conclusion from our studies is that the heterogeneity of malignant cells present in ovarian cancer is the result of the multipotential capacity of E/M-MP cells for differentiation.

The concept of a hierarchy of pluripotent progenitors that fluctuates during tumor growth and under selective pressure is not without precedents. Studies on leukemia-initiating cells indicate that there is probably not a single cancer stem cell, but different groups of stem cells that can change their phenotype depending on external factors. Studies in xenograft models have shown that multiple subclones capable of leukemia initiation arise in parallel, and that most of the clones that initially form a tumor do not survive long term and do not have the capacity for self-renewal because they disappeared upon retransplantation [3].

Until recently, it was thought that tumor-initiating cells are a rare subpopulation in cancers. Nevertheless, improvements in xenotransplantation models and the use of syngeneic mouse models of breast cancer have shown that the number of tumor-initiating cells is much larger [16]. It is still elusive whether these findings can be generalized to other cancers, including ovarian cancer. Our findings that large percentages of $\mathrm{E} / \mathrm{M}$ cells have tumor-forming abilities support this. Notably, the CSC hypothesis does not rely on the size of the cancer-initiating population, but more importantly on the presence of a hierarchy of tumor-forming, multipotent cells.

CD133 has been used to enrich for cells with tumor-initiating ability from a variety of human solid tumors from the brain, prostate, liver, breast and colon [42], but there are also studies that question the value of CD133 as a putative CSC marker, particularly in colon cancer and melanoma [16]. Few attempts have been undertaken to further characterize the $\mathrm{CD} 133^{+}$ population of cancer cells. In human breast cancer cell lines, it has been found that an ALDEFLUOR-positive CD44 ${ }^{+}$subpopulation of $\mathrm{CD} 133^{+}$cells was more enriched for tumor-initiating cells than ALDEFLUOR-negative CD44- $/ \mathrm{CD} 133^{+}$cells [42]. In osteosarcoma, a $\mathrm{CD} 133^{+} / \mathrm{ABCG} 2^{+} / \mathrm{SP}^{+}$subset was enriched for cells with CSC features, such as the formation of spheres/clusters in serum-free medium with high clonogenic efficiency [37]. A clonal cell expansion model in glioblastoma recently revealed multiple tumor-initiation populations with different potential for hierarchical differentiation and aggressiveness. These populations were either positive or negative for CD133, whereby one fraction of CD133 negative cells could also give rise to CD133+ cells [43]. Our study confirms earlier reports that in ovarian cancer the $\mathrm{CD}_{133^{+}}$population is enriched in tumor-forming cells when compared to $\mathrm{CD} 133^{-}$cells $[11,44]$. We also found that in biopsies from different ovarian cancer patients (Figure S4) and xenograft tumors (Figure 3), CD $133^{+}$cells comprise a large fraction $(\sim 30 \%)$ of tumor cells. This determines that further differentiation of cells within the population of $\mathrm{CD} 133^{+}$cells is needed. Our study is the first to utilize E-cadherin and Tie2 as a marker to isolate different $\mathrm{CD} 33^{+}$fractions from tumor material. Potentially, other endothelial markers (e.g. VCAM-1) could be used for a similar purpose. Notably, even though $\mathrm{CD} 133^{+} / \mathrm{Tie} 2^{+}$fail to efficiently initiate tumor growth in mice, it remains questionable whether 
these cells also have a growth disadvantage in established tumors. The positivity for proliferation marker Ki-67 among CD133 ${ }^{+}$cells in xenografts would argue against this (Figure S6B). Furthermore, it is possible that tumors arise at a later time point, since primary ovarian cancer cells from patient biopsies display much greater heterogeneity than established cancer cell lines. Ultimately, the analysis of tumor-forming abilities most likely resembles only a "snapshot" of tumors or tumor cell cultures at time of analysis. Such analyses might therefore underestimate the potential of less tumorigenic cells that have the potential for de-differentiation under different conditions.

In our study the loss of CD133 was linked to EMT in in vitro cultures. Surface CD $133^{+}$mesenchymal cells were rarely observed, whereas mesenchymal cells often harbored CD133 in the cytoplasm. Notably, CD133 has been recognized as a marker for developing epithelium [45]. Therefore, the isolation of cells from (mainly mesenchymal) in vitro cultures based on surface CD133 might not assess the complete tumor-forming population. An important conclusion from our study is that CD133 mainly marks a population of $\mathrm{E} / \mathrm{M}$ hybrid cells, which is adaptable to different conditions and able to differentiate into either epithelial or mesenchymal cells depending on the provided environment. We therefore suggest that CD133 should only be used in combination with epithelial and mesenchymal markers in order to identify and study tumor-initiating cells within ovarian cancers.

The overall picture of potential cancer stem cells that we obtained from our study is relatively complex. It involves the existence of subsets of tumor forming cells with distinct differentiation potential. The composition of these subsets is transitory, and can shift bi-directionally, depending on external conditions and the stage of tumor growth. The understanding of this phenotypic complexity has important implications for ovarian cancer therapy.

\section{Methods}

\section{Tissue Culture}

Ovarian cancer biopsies were provided by the Pacific Ovarian Cancer Research Consortium (POCRC) Specimen Repository without any cconfidential information which would serve to identify a patient (Fred Hutchinson Cancer Research Center IRB protocol \# 6289). Tumor tissue from biopsies was dissected into $4 \mathrm{~mm}$ pieces and digested for 2 hours at $37^{\circ} \mathrm{C}$ with $1 \mathrm{mg} / \mathrm{ml}$ collagenase/dispase (Roche) and $0.1 \mathrm{mM} \mathrm{CaCl}_{2}$ (Sigma) in RPMI 1640 (Gibco). This was followed by incubation with versene (Gibco) (1:1 vol/vol) for 1 hour. The protease digestion was stopped by the addition of FBS (Gibco) to a final concentration of $10 \%$. Cells were passed through a $70 \mu \mathrm{m}$ cell strainer (BD Falcon) using the plunger of a $5 \mathrm{ml}$ syringe (Becton Dickinson). The cell strainer was washed with $25 \mathrm{ml}$ RPMI and the total flow-through was pelleted. The pellet was resuspended in $5 \mathrm{ml} \mathrm{RPMI/10 \% FBS}$ with $1 \mathrm{mg} / \mathrm{ml}$ DNaseI (Roche) and incubated for $30 \mathrm{~min}$ at $37^{\circ} \mathrm{C}$. Cells were pelleted again and subjected to a ficoll gradient $(10 \mathrm{ml}$ underlay, Stem Cell Technologies) separation step if high amounts of erythrocytes were observed. The resulting cultures were kept in MEGM (Lonza) at low serum levels $(1-2 \%)$ and in high cell densities, in order to minimize fibroblast growth. Clonal ovc316$\mathrm{XC}$ cultures were established as published previously [33]. Clones were established by limited dilution ( 0.5 cells seeded per well in a 96 well plate) to ensure single cell suspension. Single cell plating was confirmed by light microscopy and wells containing more than one cell were excluded from further culturing. Further rounds of subcloning of clonal E/M cultures yielded the same secondary and tertiary clonal cultures with hybrid $\mathrm{E} / \mathrm{M}$ phenotype and tumorforming ability. SKOV3-ip1, OVCAR-3, and OVCAR-5 cells were cultured in MEGM/DMEM (Lonza/Gibco, 50\%/50\% v/v) supplemented with $10 \%$ FBS and 1\% Penicillin/Streptomycin.

\section{Inhibitors}

CD $133^{+}$cells were isolated by column isolation (Miltenyi Biotec). A total of $2.5 \times 10^{5} \mathrm{CD} 133^{+}$cells were seeded in 12 well plates (BD Falcon) and subsequently treated with inhibitors diluted in fresh MEGM medium. All inhibitors were purchased from Calbiochem and used in the following concentrations: Rafl inhibitor $(20 \mu \mathrm{M})$, U0126 $(40 \mu \mathrm{M})$, p38 inhibitor III $(10 \mu \mathrm{M})$, JNK inhibitor II (100 nM). Inhibitors were replaced with fresh medium every $48 \mathrm{hrs}$ and cells were passaged (1:2), when the first experimental culture (p38 inhibitor-treated) reached 100\% confluence. Cells were analyzed by flow cytometry after 21 days. In order to evaluate proliferation rates, $10 \%(\mathrm{v} / \mathrm{v})$ of each individual experimental setup from passage 3 were seeded into 96 well plates in triplicate. Cells were further cultured in the presence of inhibitors for 3 days prior to readout by MTT assay.

\section{MTT assay}

MTT assays were carried out in 96 well plates in triplicate. A total of $15 \mu \mathrm{l}$ of a stock solution of $5 \mathrm{mg} / \mathrm{ml} 3-(4,5-$ Dimethylthiazol2-yl)-2,5-diphenyltetrazolium bromide (Sigma) per well was applied for $2 \mathrm{hrs}$. Medium was aspirated, formazide crystals were disolved in DMSO, and absorbance was measured at $495 \mathrm{~nm}$ using a plate reader. The percentage of viable cells is relative to mock treated cells.

\section{Flow cytometry}

Adherent cells were detached from tissue culture plates by treatment with Versene (Gibco) for 30-60 min. Cells were then transferred into $15 \mathrm{ml}$ tubes (BD Falcon) and washed with RPMI 1640 supplemented with $10 \%$ FBS. Cell pellets were resuspended in ice-cold PBS with $1 \%$ FBS in order to block unspecific antibody binding. Then $2 \times 10^{5}$ cells were incubated with antibodies in $5 \mathrm{ml}$ round bottom tubes (BD Falcon) in a total of $100 \mu \mathrm{l}$ for $45 \mathrm{~min}$ on ice. All subsequent incubation steps were carried out in the dark. Cells were washed with $3 \mathrm{ml} \mathrm{PBS}+1 \% \mathrm{FBS}$ and centrifuged at $400 \mathrm{~g}$ for $5 \mathrm{~min}$ at $4^{\circ} \mathrm{C}$. After surface antigen staining, cells were fixed with $4 \%$ paraformaldehyde for $15 \mathrm{~min}$ on ice. Following a PBS $+1 \%$ FBS wash, cells were either subjected to flow cytometry analysis or prepared for intracellular antigen staining (vimentin, $\mathrm{Ki}-67$ ) by treatment with $0.1 \%$ Triton $\times 100$ (Sigma) for $15 \mathrm{~min}$ at room temperature. If needed, fluorophor-labeled secondary antibodies were used against the appropriate host. Samples were filtered $(70 \mu \mathrm{m}$, Becton Dickinson) and then analyzed using either a BD FACSCanto or BD FACScalibur flow cytometer (Becton Dickenson). Unspecific background of individual channels was determined with isotype controls and color compensation was done on single color-stained samples. Dead cells were excluded with 7AAD (Invitrogen). Figures were generated using FlowJo for Macintosh (Tree Star, Inc.).

\section{Animal studies}

All experiments involving animals were conducted in accordance with the institutional guidelines set forth by the University of Washington and the Federation of European Laboratory Animal Science Associations for the care and use of laboratory animals. The studies were approved by the University of Washington Institutional Animal Care and Use Committee (protocol \# 310801) and the Danish Cancer Society (protocol \#2009-19). All mice were housed in specific-pathogen-free facilities. To establish subcutaneous tumors, CD17-SCID-beige mice were injected in 
the mammary fat pad with $1 \times 10^{5}$ tumor cells or indicated cell numbers using a Matrigel (BD Biosciences)/MEGM $(50 \mu \mathrm{l} / 50 \mu \mathrm{l})$ mix. Immunofluorescence analyses of tumor sections was performed as described elsewhere [46].

Limiting dilution analyses were carried out using Extreme Limiting Dilution Analysis (ELDA) [47]. Estimated numbers for frequency of tumor-initiating cells (TIC) were calculated by confidence intervals. Tumor-initiating cell populations were compared by likelihood ratio tests and obtained chi-square and $\mathrm{p}$-values are indicated.

\section{Cell sorting}

Cell sorting was performed on a pool of 8 freshly dissected ocv316-X tumor xenografts. $\mathrm{CD} 133^{+}$and $\mathrm{CD} 133^{-}$cells were isolated using the CD133/2-biotin antibody and anti-biotin microbeads according to the manufacturers protocol (Miltenyi Biotec). Three separate MACS LS columns were consecutively used to isolate high purity fractions. Following isolation, cells were either incubated with Tie2-PE antibodies or isotope control. Cell separation and cell number sorting was done with a BD Cytopia Influx. Dead cells were excluded with SYTOX Green (Invitrogen). Cells were sorted into ice-chilled 96well roundbottom plates with a Matrigel/MEGM $(50 \mu \mathrm{l} / 50 \mu \mathrm{l})$ mix and subsequently injected into mice. Purity of sorted fractions was confirmed using the BD FACScalibur flow cytometer. For separation of CD133 high $/$ E-cadherin fractions the CD133/1-PE and E-cadherin-APG antibodies were used with the BeckmanCoulter MoFlo XDP. Viable cells were isolated by sorting for 7AAD negative events. Additional studies were performed with tumor cell suspensions isolated from patient biopsies. Tumors were microdisected, homogenized and digested with collagenase/dispase as elsewhere http://www.miltenyibiotec. com/download/protocols_gentlemacs_en/1624/gentleMACStumor_human-01.pdf. To re-express cell surface molecules, tumor cells were cultured in suspensions in a rotating tube for 5 hours and then subjected to MACS and FACs as described above.

\section{Co-culture of CD133 ${ }^{\text {high }}$ cells with epithelial or mesenchymal cells}

$1 \times 10^{4}$ sorted CD133 $3^{\text {high }} / \mathrm{E}$-cadherin ${ }^{\text {high }}$ or $\mathrm{CD} 133^{\text {high }} / \mathrm{E}$ cadherin $^{\text {low }}$ cells were cultured either alone or in co-culture with $1 \times 10^{5}$ epithelial or mesenchymal cells derived from clonal ovc316-XC cells in $6 \mathrm{~cm}$ dishes (Nunc). Clonal ovc316-XC cultures were labeled using the PHK26 membrane stain (Sigma) prior to co-culturing. Cell-labeling was carried out according to the manufacturers protocol with an extended labeling time of $15 \mathrm{~min}$ followed by three wash steps.

\section{Western Blot}

Xenograft tumor tissue was dissected, manually homogenized (glass homogenizer) and incubated for $30 \mathrm{~min}$ in protein lysis buffer (20mM Hepes (pH 7.5), 2mM EGTA, 10\% glycerol, 1\% Triton $\times 100,1 \mathrm{mM}$ PMSF, $200 \mu \mathrm{M} \mathrm{Na} \mathrm{VO}_{4}$ [all Sigma], and protease inhibitors [Complete Protease Inhibitor Cocktail, Roche]) on ice. Confluent cultured cells were washed with ice-cold PBS twice and then lysed for $30 \mathrm{~min}$ in protein lysis buffer on ice. After 30 seconds of sonication (Branson Sonifier 250, intensity 4 of 10) on ice, samples were pelleted $\left(10 \mathrm{~min}, 4^{\circ} \mathrm{C}, 15,000 \mathrm{RPM}\right.$, Eppendorf table centrifuge) and protein containing supernatant stored at $-80^{\circ} \mathrm{C}$. A total of $15 \mu \mathrm{g}$ of total protein was used for Western blotting. Protein samples were boiled $\left(5 \mathrm{~min}, 95^{\circ} \mathrm{C}\right)$ and separated by polyacrylamide gel electrophoresis using $4-15 \%$ gradient gels (BioRad) followed by transfer onto nitrocellulose membranes according to the supplier's protocol (Mini ProteanIII, BioRad). Membranes were blocked in PBS, 0.1\% Tween20 (PBS$\mathrm{T}$, Sigma) $+5 \%$ dry milk powder (BioRad). Incubation times for primary and secondary antibodies were 2 hours and 1 hour at room temperature, respectively. Antibodies were diluted in PBS-T $+2 \%$ dry-milk powder. Membranes were washed 5 times in PBS-T between antibody incubations, and films were developed using ECL plus (Amersham).

\section{Immunofluorescence}

Cells were cultured in 8 chamber glass slides (BD Falcon), washed twice with ice-cold PBS and then fixed with methanol/ acetone $(1: 1 \mathrm{vol} / \mathrm{vol})$ for $15 \mathrm{~min}$ at $4^{\circ} \mathrm{C}$. After fixation cells were washed with PBS twice and blocked with $500 \mu \mathrm{l}$ PBS/2\% dry-milk powder for $20 \mathrm{~min}$ at room temperature. Antibody staining was performed in $100 \mu \mathrm{l} \mathrm{PBS}$ for $90 \mathrm{~min}$ at $37^{\circ} \mathrm{C}$ or $4^{\circ} \mathrm{C}$ overnight. If needed, fluorophor-labeled secondary antibodies directed against the appropriate host, were applied for $45 \mathrm{~min}$ at room temperature after 3 washes with PBS. After a further 3 washes with PBS, glass slides were mounted using VECTASHIELD with DAPI (Vector Labs). All immunofluorescence pictures were taken with a Leica DM1000 microscope featuring a Leica DFC FX camera (Leica Microsystems). Tumor sections of patient material or xenografts were snap frozen embedded in OCT compound (Tissue-Tek) on dry ice. OCT embedded tissues were then stored at $-80^{\circ} \mathrm{C}$ and equilibrated to $-20^{\circ} \mathrm{C}$ for at least 1 hour prior to sectioning. Tumor tissue was sliced (8 microns) using a Leica CM 1850 cryostat (Leica Microsystems) and then transferred onto Superfrost slides (Fisher Scientific). Slides were fixed in acetone (Fisher Scientific) for $10 \mathrm{~min}$ at $-20^{\circ} \mathrm{C}$. After two rinses with PBS (Sigma) slides were blocked with $2 \%$ milk powder (BioRad) in PBS for $20 \mathrm{~min}$ at room temperature.

\section{Antibodies}

All antibodies and the dilutions used in this study are detailed in Table S2.

\section{Supporting Information}

Figure S1 Transdifferentiation of clonal epithelial cells into mesenchymal cells. A) Epithelial clone derived from ovc316-XC at passage 8 and passage 20 stained for the epithelial markers E-cadherin and Claudin 7. B) Passage 20 cells stained for the mesenchymal marker N-p120. The scale bar is $40 \mu \mathrm{m}$.

(PDF)

Figure S2 Gharacterization of $\mathbf{E} / \mathbf{M}$ hybrid cells. A) Ecadherin $^{\text {high }}$ cells contain low amounts of CD31, caldesmon, and VCAM-1, whereas E-cadherin ${ }^{\text {low }}$ cells stain highly positive for these markers. B) Analysis of pluripotency markers. E-cadherin ${ }^{\text {low }}$ cells express high levels of nuclear-localized Nanog and Oct4. Most cells in ovc316 cultures contain high amounts of nuclear Sox2. C) Correlation of membrane-bound beta-catenin (green) and claudin 7 (red). Cells low on membrane-claudin 7 predominantly localize beta-catenin to the cytoplasm/nucleus. Shown are images from ovc316-XC. D) Staining for human mitochondrial marker. Immunofluorescence analysis of ovc0117-PC, ovc0122PC, ovc100506-XC, and ovc100728-XC revealed similar results. (PDF)

Figure S3 Gharacterization of different cellular phenotypes ovarian cancer cultures. A) Analysis of E-cadherin (x axis), CD44 (y axis), and CD133 (histogram). Shown are density 
blots of the whole culture (left panel) and of the CD $133^{+}$subfraction within the culture (right panel). $\mathrm{CD} 133^{+}$cancer stem-like cells are highly positive for CD44 and are divided into epithelial and mesenchymal phenotypes. The mesenchymal sub-fraction enriches during passaging and concomitant EMT in culture ovc316. The total amount of CD133 dramatically decreases after passaging. Shown are studies with ovc316-XC. B) Analysis of Ecadherin (x axis), CD44 (y axis), and Tie2 (histogram). Shown are density blots of the whole culture (left panel) and of the Tie $2^{+}$subfraction within the culture (right panel). $\mathrm{Tie}^{+}$progenitor cells have an epithelial phenotype and are lower in CD44 levels than $\mathrm{CD}_{133^{+}}$cells. Shown are studies with ovc316-XC. G) Flow cytometry analysis of clonal ovc316-XC cultures. Non-tumorigenic epithelial and mesenchymal clones are low on CD133. Tumorigenic E/M hybrid cultures contain $\mathrm{CD}_{133^{+}}$cells of epithelial and mesenchymal phenotypes that are highly positive for CD44. D) Sphere formation after growth factor starvation in primary ovarian cancer cultures from different biopsies. Primary cultures were grown In MEBM medium for 5 days. Shown are studies with four primary cultures.

(PDF)

Figure S4 E/M cells subsets in biopsies from ovarian cancer patients. A) Sections from patient biopsies were stained for the epithelial marker E-cadherin and the mesenchymal marker Vimentin. B and $\mathbf{G}$ ) Sections from patient biopsies were stained for E-cadherin and CD133 (B) or E-cadherin and Tie2 (C). $\mathrm{CD}_{133^{+}}$areas with differential E-cadherin staining are marked. Shown are sections of ovc1208-biopsy, ovc0122 biopsy, and ovc0117-biopsy. Immunofluoresence analysis of ovc1123-biopsy, ovc0111-biopsy, ovc0116-biopsy, ovc123-biopsy, and ovc100506biopsy resulted in similar staining.

(PDF)

Figure S5 Sections of ovc31-X xenografts. A) Global view of a xenograft tumor assembled from different images. B) Higher magnification of an ovc316-X xenograft section to visualize two different $\mathrm{CD}_{133^{+}}$subsets, including areas with membrane Ecadherin and areas with punctated cytoplasmic E-cadherin.

(PDF)

\section{References}

1. Knoblich JA (2008) Mechanisms of asymmetric stem cell division. Cell 132: 583-597.

2. Passegue E, Jamieson CH, Ailles LE, Weissman IL (2003) Normal and leukemic hematopoiesis: are leukemias a stem cell disorder or a reacquisition of stem cell characteristics? Proc Natl Acad Sci U S A 100 Suppl 1: 11842-11849.

3. Hope KJ, Jin L, Dick JE (2004) Acute myeloid leukemia originates from a hierarchy of leukemic stem cell classes that differ in self-renewal capacity. Nat Immunol 5: 738-743.

4. Al-Hajj M, Wicha MS, Benito-Hernandez A, Morrison SJ, Clarke MF (2003) Prospective identification of tumorigenic breast cancer cells. Proc Natl Acad Sci U S A 100: 3983-3988.

5. Galli R, Binda E, Orfanelli U, Cipelletti B, Gritti A, et al. (2004) Isolation and characterization of tumorigenic, stem-like neural precursors from human glioblastoma. Cancer Res 64: 7011-7021.

6. O'Brien CA, Pollett A, Gallinger S, Dick JE (2007) A human colon cancer cell capable of initiating tumour growth in immunodeficient mice. Nature 445: 106-110.

7. Prince ME, Sivanandan R, Kaczorowski A, Wolf GT, Kaplan MJ, et al. (2007) Identification of a subpopulation of cells with cancer stem cell properties in head and neck squamous cell carcinoma. Proc Natl Acad Sci U S A 104: 973-978.

8. Ophorst OJ, Radosevic K, Klap JM, Sijtsma J, Gillissen G, et al. (2007) Increased immunogenicity of recombinant Ad35-based malaria vaccine through formulation with aluminium phosphate adjuvant. Vaccine 25: 6501-6510.

9. Collins AT, Berry PA, Hyde C, Stower MJ, Maitland NJ (2005) Prospective identification of tumorigenic prostate cancer stem cells. Cancer Res 65: 10946-10951.
Figure S6 Analysis of CD133 fractions. A) Sections of tumors derived from sorted $\mathrm{CD}_{133^{+}}$and $\mathrm{CD} 133^{-}$cells. B) Flow cytometry analysis for differentiation and proliferation markers. $\mathrm{CD}_{133^{+}}$and $\mathrm{CD} 133^{-}$cells within ovc316-X xenograft tumors are positive for Ki-67. CD133- cells contain higher amounts of Ki-67 negative cells than the $\mathrm{CD} 133^{+}$cell fraction.

(PDF)

Figure S7 Ovarian cancer cell lines contain $\mathrm{CD}_{133^{+}}$and Tie2 $^{+}$cells. The majority of $\mathrm{CD}_{1} 33^{+}$and $\mathrm{Tie}^{+}$cells are mutually exclusive. $\mathrm{Tie} 2^{+} / \mathrm{CD} 133^{+}$double positive cells have lower levels of $\mathrm{CD} 133^{+}$than $\mathrm{CD} 133^{+} / \mathrm{Tie}^{-}$cells. A) SKOV3-ip 1 cells. B) OVCAR-5 cells. G) OVCAR-3 cells (PDF)

Figure S8 Expression of E-cadherin and stem cell markers CD133 and Nanog after growth factor/serum starvation of passage 18 ovc316-XC cells.

(PDF)

Table S1

(PDF)

Table S2

(PDF)

\section{Acknowledgments}

We thank Daniel Stone for critically editing the manuscript. We are grateful to Nelly Auersperg, Ingegerd Hellstrom, and Paul Brinkkoetter for helpful discussions and providing valuable material. Furthermore, we thank the Canadian Ovarian Tissue Bank for providing primary ovarian surface epithelial cells.

\section{Author Contributions}

Conceived and designed the experiments: RS AL. Performed the experiments: AL ZYL YL PS SP PH IB JP. Analyzed the data: RS PS TM AH JB AL. Contributed reagents/materials/analysis tools: CD NU. Wrote the paper: RS AL.

10. Bapat SA, Mali AM, Koppikar CB, Kurrey NK (2005) Stem and progenitor-like cells contribute to the aggressive behavior of human epithelial ovarian cancer. Cancer Res 65: 3025-3029.

11. Baba T, Convery PA, Matsumura N, Whitaker RS, Kondoh E, et al. (2009) Epigenetic regulation of CD133 and tumorigenicity of CD133+ ovarian cancer cells. Oncogene 28: 209-218.

12. Zhang S, Balch C, Chan MW, Lai HC, Matei D, et al. (2008) Identification and characterization of ovarian cancer-initiating cells from primary human tumors. Cancer Res 68: 4311-4320.

13. Fang D, Nguyen TK, Leishear K, Finko R, Kulp AN, et al. (2005) A tumorigenic subpopulation with stem cell properties in melanomas. Cancer Res 65: 9328-9337.

14. Clarke MF, Dick JE, Dirks PB, Eaves CJ, Jamieson CH, et al. (2006) Cancer stem cells-perspectives on current status and future directions: AACR Workshop on cancer stem cells. Cancer Res 66: 9339-9344.

15. Gupta PB, Chaffer CL, Weinberg RA (2009) Cancer stem cells: mirage or reality? Nat Med 15: 1010-1012.

16. Quintana E, Shackleton M, Sabel MS, Fullen DR, Johnson TM, et al. (2008) Efficient tumour formation by single human melanoma cells. Nature 456: 593-598.

17. Turley EA, Veiseh M, Radisky DC, Bissell MJ (2008) Mechanisms of Disease: epithelial-mesenchymal transition-does cellular plasticity fuel neoplastic progression? Nat Glin Pract Oncol.

18. Christiansen JJ, Rajasekaran AK (2006) Reassessing epithelial to mesenchymal transition as a prerequisite for carcinoma invasion and metastasis. Cancer Res 66: 8319-8326.

19. Thiery JP, Huang R (2005) Linking epithelial-mesenchymal transition to the well-known polarity protein Par6. Dev Cell 8: 456-458. 
20. Wong AS, Auersperg N (2002) Normal ovarian surface epithelium. Cancer Treat Res 107: 161-183.

21. Auersperg N, Ota T, Mitchell GW (2002) Early events in ovarian epithelial carcinogenesis: progress and problems in experimental approaches. Int J Gynecol Cancer 12: 691-703.

22. Sundfeldt K, Piontkewitz Y, Ivarsson K, Nilsson O, Hellberg P, et al. (1997) Ecadherin expression in human epithelial ovarian cancer and normal ovary. Int J Cancer 74: 275-280.

23. Peralta Soler A, Knudsen KA, Tecson-Miguel A, McBrearty FX, Han AC, et al. (1997) Expression of E-cadherin and N-cadherin in surface epithelial-stromal tumors of the ovary distinguishes mucinous from serous and endometrioid tumors. Hum Pathol 28: 734-739.

24. Patel IS, Madan P, Getsios S, Bertrand MA, MacCalman CD (2003) Cadherin switching in ovarian cancer progression. Int J Cancer 106: 172-177.

25. Hudson LG, Zeineldin R, Stack MS (2008) Phenotypic plasticity of neoplastic ovarian epithelium: unique cadherin profiles in tumor progression. Clin Exp Metastasis 25: 643-655.

26. Cho EY, Choi Y, Chae SW, Sohn JH, Ahn GH (2006) Immunohistochemical study of the expression of adhesion molecules in ovarian serous neoplasms. Pathol Int 56: 62-70.

27. Voutilainen KA, Anttila MA, Sillanpaa SM, Ropponen KM, Saarikoski SV, et al. (2006) Prognostic significance of E-cadherin-catenin complex in epithelial ovarian cancer. J Clin Pathol 59: 460-467.

28. Imai T, Horiuchi A, Shiozawa T, Osada R, Kikuchi N, et al. (2004) Elevated expression of E-cadherin and alpha-, beta-, and gamma-catenins in metastatic lesions compared with primary epithelial ovarian carcinomas. Hum Pathol 35: 1469-1476.

29. Ahmed N, Maines-Bandiera S, Quinn MA, Unger WG, Dedhar S, et al. (2006) Molecular pathways regulating EGF-induced epithelio-mesenchymal transition in human ovarian surface epithelium. Am J Physiol Cell Physiol 290: C1532-1542.

30. Brabletz T, Jung A, Spaderna S, Hlubek F, Kirchner T (2005) Opinion: migrating cancer stem cells - an integrated concept of malignant tumour progression. Nat Rev Cancer 5: 744-749.

31. Come C, Magnino F, Bibeau F, De Santa Barbara P, Becker KF, et al. (2006) Snail and slug play distinct roles during breast carcinoma progression. Clin Cancer Res 12: 5395-5402.

32. Arnoux V, Come C, Kusewitt D, Hudson L, Savagner P (2005) Cutaneous Wound Reepithelization: A partial and reversible EMT. Springer, Berlin Rise and Fall of epithelial phenotype: concepts of epithelial-mesenchymal transition. pp 111-134.
33. Strauss R, Sova P, Liu Y, Li ZY, Tuve S, et al. (2009) Epithelial phenotype confers resistance of ovarian cancer cells to oncolytic adenoviruses. Cancer Res 69: 5115-5125.

34. Martin V, Liu D, Fueyo J, Gomez-Manzano C (2008) Tie2: a journey from normal angiogenesis to cancer and beyond. Histol Histopathol 23: 773-780.

35. Martin V, Xu J, Pabbisetty SK, Alonso MM, Liu D, et al. (2009) Tie2-mediated multidrug resistance in malignant gliomas is associated with upregulation of ABC transporters. Oncogene 28: 2358-2363.

36. Fong MY, Kakar SS (2010) The role of cancer stem cells and the side population in epithelial ovarian cancer. Histol Histopathol 25: 113-120.

37. Tirino V, Desiderio V, d'Aquino R, De Francesco F, Pirozzi G, et al. (2008) Detection and characterization of CD133+ cancer stem cells in human solid tumours. PLoS ONE 3: e3469.

38. Mani SA, Guo W, Liao MJ, Eaton EN, Ayyanan A, et al. (2008) The epithelialmesenchymal transition generates cells with properties of stem cells. Cell 133: 704-715.

39. Kong D, Banerjee S, Ahmad A, Li Y, Wang Z, et al. (2010) Epithelial to mesenchymal transition is mechanistically linked with stem cell signatures in prostate cancer cells. PLoS One 5: e12445.

40. Ricci-Vitiani L, Pallini R, Biffoni M, Todaro M (2010) Tumour vascularization via endothelial differentiation of glioma stem-like cells. Nature doi: 10.1038/ nature09557.

41. Wang R, Chadalavada K, Wilsjire J, Rowalik U, Hovinga KE (2010) Glioma stem-like cells give rise to tumour endothelium. Nature doi: 10.1038/ nature09624.

42. Wu Y, Wu PY (2009) CD133 as a marker for cancer stem cells: progresses and concerns. Stem Cells Dev 18: 1127-1134.

43. Chen R, Nishimura MC, Bumbaca SM, Kharbanda S, Forrest WF, et al. (2010) A hierarchy of self-renewing tumor-initiating cell types in glioblastoma. Cancer Cell 17: 362-375.

44. Curley MD, Therrien VA, Cummings CL, Sergent PA, Koulouris CR, et al. (2009) CD133 expression defines a tumor initiating cell population in primary human ovarian cancer. Stem Cells 27: 2875-2883.

45. Richardson GD, Robson GN, Lang SH, Neal DE, Maitland NJ, et al. (2004) CD133, a novel marker for human prostatic epithelial stem cells. J Cell Sci 117: 3539-3545.

46. Li ZY, Ni S, Yang X, Kiviat N, Lieber A (2004) Xenograft models for liver metastasis: Relationship between tumor morphology and adenovirus vector transduction. Mol Ther 9: 650-657.

47. Hu Y, Smyth GK (2009) ELDA: extreme limiting dilution analysis for comparing depleted and enriched populations in stem cell and other assays. J Immunol Methods 347: 70-78. 